\title{
Mitochondrial contact site and cristae organizing system (MICOS) machinery supports heme biosynthesis by enabling optimal performance of ferrochelatase
}

\author{
Jonathan V. Dietz ${ }^{\text {a }}$, Mathilda M. Willoughby ${ }^{\text {b,c }}$, Robert B. Piel III ${ }^{\mathrm{d}, 1}$, Teresa A. Ross ${ }^{\mathrm{d}, 2}$, \\ Iryna Bohovych $^{\mathrm{a}}$, Hannah G. Addis ${ }^{\mathrm{e}}$, Jennifer L. Fox ${ }^{\mathrm{e}}$, William N. Lanzilotta ${ }^{\mathrm{d}}$, \\ Harry A. Dailey ${ }^{\text {d,f }}$, James A. Wohlschlegel ${ }^{\mathrm{g}}$, Amit R. Reddi ${ }^{\mathrm{b}, \mathrm{c}}$, Amy E. Medlock ${ }^{\mathrm{d}, \mathrm{h}}$, \\ Oleh Khalimonchuk ${ }^{a, i, j, *}$

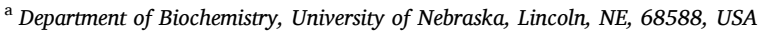 \\ ${ }^{\mathrm{b}}$ School of Chemistry and Biochemistry and School of Biological Sciences, Georgia Institute of Technology, Atlanta, GA, 30332, USA \\ ${ }^{\text {c }}$ Parker Petit Institute for Bioengineering and Biosciences, Georgia Institute of Technology, Atlanta, GA, 30332, USA \\ ${ }^{\mathrm{d}}$ Department of Biochemistry and Molecular Biology, University of Georgia, Athens, GA, 30602, USA \\ ${ }^{\mathrm{e}}$ Department of Chemistry and Biochemistry, College of Charleston, Charleston, SC, 29424, USA \\ ${ }^{\mathrm{f}}$ Department of Microbiology, University of Georgia, Athens, GA, 30602, USA \\ ${ }^{g}$ Department of Biological Chemistry, University of California, Los Angeles, CA, 90095, USA \\ ${ }^{\mathrm{h}}$ Augusta University/University of Georgia Medical Partnership, Athens, GA, 30602, USA \\ ${ }^{i}$ Nebraska Redox Biology Center, University of Nebraska, Lincoln, NE, 68588, USA \\ ${ }^{\mathrm{j}}$ Fred \& Pamela Buffett Cancer Center, Omaha, NE, 68198, USA
}

\section{A R T I C L E I N F O}

\section{Keywords:}

Mitochondria

Heme

MICOS

Ferrochelatase

Yeast

\begin{abstract}
A B S T R A C T
Heme is an essential cofactor required for a plethora of cellular processes in eukaryotes. In metazoans the heme biosynthetic pathway is typically partitioned between the cytosol and mitochondria, with the first and final steps taking place in the mitochondrion. The pathway has been extensively studied and its biosynthetic enzymes structurally characterized to varying extents. Nevertheless, understanding of the regulation of heme synthesis and factors that influence this process in metazoans remains incomplete. Therefore, we investigated the molecular organization as well as the physical and genetic interactions of the terminal pathway enzyme, ferrochelatase (Hem15), in the yeast Saccharomyces cerevisiae. Biochemical and genetic analyses revealed dynamic association of Hem15 with Mic60, a core component of the mitochondrial contact site and cristae organizing system (MICOS). Loss of MICOS negatively impacts Hem15 activity, affects the size of the Hem15 high-mass complex, and results in accumulation of reactive and potentially toxic tetrapyrrole precursors that may cause oxidative damage. Restoring intermembrane connectivity in MICOS-deficient cells mitigates these cytotoxic effects. These data provide new insights into how heme biosynthetic machinery is organized and regulated, linking mitochondrial architecture-organizing factors to heme homeostasis.
\end{abstract}

\section{Introduction}

Heme is an essential cofactor and signaling molecule required for diverse physiological processes, from the mitochondrial electron transport chain to oxygen transportation through the bloodstream [1-4]. Most metazoans synthesize heme through a highly conserved and well-characterized eight-step pathway [5]. In the first step, the mitochondrial enzyme aminolevulinic acid synthase (Alas; ALAS in humans; Hem 1 in yeast) catalyzes the condensation of glycine and succinyl-CoA to form aminolevulinic acid (ALA), which is then transported out of the mitochondrion by an as-yet-uncharacterized transporter. Once in the cytosol, two ALA molecules are condensed into a monopyrrole,

\footnotetext{
* Corresponding author. Department of Biochemistry, University of Nebraska, Lincoln, NE, 68588, USA.

E-mail address: okhalimonchuk2@unl.edu (O. Khalimonchuk).

1 Current address: Animal Disease Research Unit, Agricultural Research Service, U.S. Department of Agriculture, Pullman, WA 99164, USA and.

2 USDA-ARS, US National Poultry Research Center, Athens, GA 30605, USA.
} 
porphobilinogen, by the enzyme porphobilinogen synthase (Pbgs); subsequently, four porphobilinogen molecules are joined together by hydroxymethylbilane synthase (Hmbs) to form the linear tetrapyrrole hydroxymethylbilane (HMB). HMB then undergoes cyclization to form uroporphyrinogen III (catalyzed by uroporphyrinogen synthase, Uros) and decarboxylation of its pyrrole acetate side chains (catalyzed by uroporphyrinogen decarboxylase, Urod) to yield coproporphyrinogen III. In Saccharomyces cerevisiae, coproporphyrinogen III is converted to protoporphyrinogen IX by coproporphyrinogen oxidase (Cpox) in the cytosol $[6,7]$, while in humans this reaction occurs in the mitochondrial intermembrane space (IMS) $[8,9]$.

Protoporphyrinogen IX is transported into the mitochondrial matrix and converted to protoporphyrin IX (PPIX) by the matrix-localized enzyme protoporphyrinogen oxidase (Ppox) [10]. How protoporphyrinogen IX is transported across the inner mitochondrial membrane (IM) is currently unclear though evidence suggests that the porphyrinogen transporter TMEM14C facilitates this process during erythroid cell maturation [11]. The final step of heme synthesis is catalyzed by ferrochelatase (Fech; FECH in humans; Hem15 in yeast), which resides on the matrix side of the IM [12] and mediates the insertion of ferrous iron into PPIX, thereby yielding heme (also known as protoheme or heme $b$ ).

Even though the proteins involved in heme synthesis have been structurally characterized and in some cases examined mechanistically $[3,13]$, the processes by which the relative rates of heme synthesis are regulated remain obscure. Understanding of this regulation is mainly limited to the transcriptional level in multicellular organisms with erythrocytes. In these organisms, most heme production occurs in the developing erythron, and specific transcription factors are known to play a role in regulating expression of all the biosynthetic enzymes [14]. The mechanisms of regulation of heme synthesis for many other cells in these organisms and in unicellular eukaryotes like $S$. cerevisiae, all of which require less heme, remain uncharacterized.

In terms of enzyme activity, the rate-limiting step of the pathway in mammals is the first step (catalyzed by ALAS), with the last step (catalyzed by FECH) being the second regulatory point of the mammalian pathway [14]. In S. cerevisiae, two other pathway enzymes, Pbgs and Hmbs, have been proposed to catalyze the rate-limiting steps $[7,15]$. Recent data suggest additional levels of regulation at the post-translational level [16,17].

Proteomic studies in mammalian cells show that the mitochondrial heme biosynthetic machinery exists as a large supercomplex, termed the heme metabolon [17-19]. FECH was identified as a component of a multimeric assembly that includes ALAS and PPOX, the porphyrinogen transporter TMEM14C, and succinyl-CoA synthase $[17,18]$. The mitochondrial iron importer mitoferrin [20] and two ATP-binding cassette proteins (ABCB7 and ABCB10) [20-22] have also been shown to bind to FECH. Additional candidate interaction partners of FECH include factors that mediate IM dynamics and ultrastructure [17,19], most notably components of the conserved mitochondrial contact site and cristae organizing system (MICOS). As suggested by its name, MICOS maintains mitochondrial cristae and contact sites between the IM and the outer mitochondrial membrane (OM) [23-25] and has been postulated to facilitate bidirectional transport of hydrophobic molecules such as phosphatidic acid [26] and coenzyme Q biosynthetic intermediates [27]. However, the physiological significance of its connection to FECH remains unaddressed.

Here, a yeast genetic model was employed to investigate the putative molecular interaction of Fech (Hem15 in yeast) with MICOS. Data from biochemical and genetic analyses are consistent with a dynamic association of Hem15 with the core MICOS component Mic60. Loss of MICOS negatively impacts Hem15 activity and results in accumulation of cytotoxic pathway intermediates. These data provide insights into how the heme biosynthetic machinery is organized and supported, linking mitochondrial architecture to heme homeostasis.

\section{Results}

\subsection{Functional Hem15 forms a high-mass complex}

Hem15 is known to exist as a homodimer [28,29], but its protein-protein interaction has not been systematically studied. To that end, an antibody was developed against Hem15, which specifically recognizes $S$. cerevisiae Hem 15 (Fig. 1A). Using this antibody and purified Hem15 as a reference, mitochondria from galactose-cultured wild type (WT) cells in the mid-log growth phase were found to contain approximately $1.0 \mathrm{ng}$ of endogenous Hem15 per milligram of mitochondrial protein (Supplementary Fig. S1A). This concentration is comparable to other mitochondrial heme synthesis enzymes as well as other IM proteins [30]. To assess the oligomerization state of Hem15, mitochondria from WT cells were lysed with digitonin and the lysate proteins subjected to sucrose gradient ultracentrifugation followed by SDS-PAGE immunoblotting of the gradient fractions. Hem15 was detected in the $\sim 250-440 \mathrm{kDa}$ molecular weight range (Fig. 1B), suggesting that endogenous yeast Hem15 exists as a high-mass complex, which likely includes additional associated components, as seen for the mammalian enzyme [17].

To determine whether the formation of this complex depends on the functional state of Hem15, the same analysis was performed using a catalytically impaired Hem 15 variant, H235C. The yeast Hem 15 residue $\mathrm{H} 235$ is equivalent to the human FECH residue H263, which is an essential catalytic histidine involved in proton abstraction prior to chelation [31]. Conversion of this residue to a cysteine yielded a variant that is stably expressed yet unable to support heme-independent growth or exhibit in vitro Fech activity (Supplementary Figs. S1B and S1C). While WT Hem 15 predominantly copurifies with bound heme, the H235C variant protein copurifies with PPIX (Supplementary Fig. S1D), further demonstrating this variant of Hem15 is impaired in catalyzing formation of heme from PPIX substrate. This H235C variant was found in fractions of lower molecular weight when mitochondrial lysates were subjected to sucrose gradient ultracentrifugation (Fig. 1B), suggesting the formation of the full complex is impaired when Hem15 is catalytically inactive. The Hem15 complex was also found to shift to lower molecular weight fractions in gradient ultracentrifugation of mitochondrial lysates derived from heme synthesis-deficient cells lacking Alas (yeast Hem1; Fig. 1B). These findings suggest that Hem15 oligomerization is at least partially dependent on the functional state of both Hem 15 and an earlier step of the heme biosynthetic pathway.

\subsection{Human ferrochelatase complements the yeast deletion strain}

Human FECH was discovered to be fully functional in yeast, complementing the yeast hem $15 \Delta$ deletion mutant (Fig. 2A), which cannot survive in the absence of exogenous heme supplementation. This finding reveals that essential interactions between Fech and other proteins are conserved in S. cerevisiae. This result is also interesting because there are known differences between the yeast and human ferrochelatase enzymes. The human enzyme, but not the yeast enzyme, possesses a [2Fe-2S] cluster, which is required for enzyme activity [32-34]. Complementation of the hem15 $\Delta$ strain with wild-type human FECH, but not the human FECH variant C406S lacking an essential [32,35] cluster ligand residue (Fig. 2A), suggests that the FECH iron-sulfur cluster is assembled properly in yeast.

\subsection{A genetic model was developed to assess Hem15 functional roles}

While re-expression of either yeast or human ferrochelatase (under the control of the native yeast ferrochelatase promoter or a constitutive, high-efficiency MET25 promoter, both on a YEp vector) in the yeast hem $15 \Delta$ strain allows cell growth in the presence of glucose, it does not always permit growth of this strain on respiratory media (Fig. 2B). This phenomenon has been observed previously [36] and has thus far posed 
A

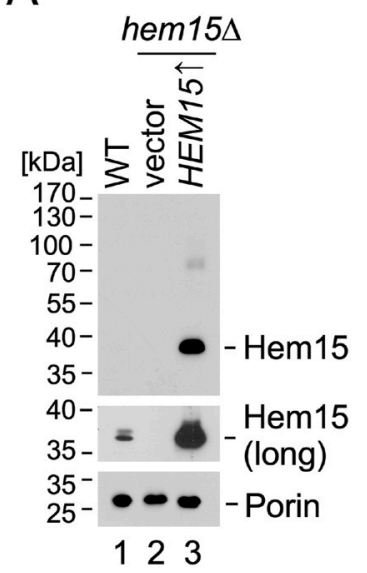

B

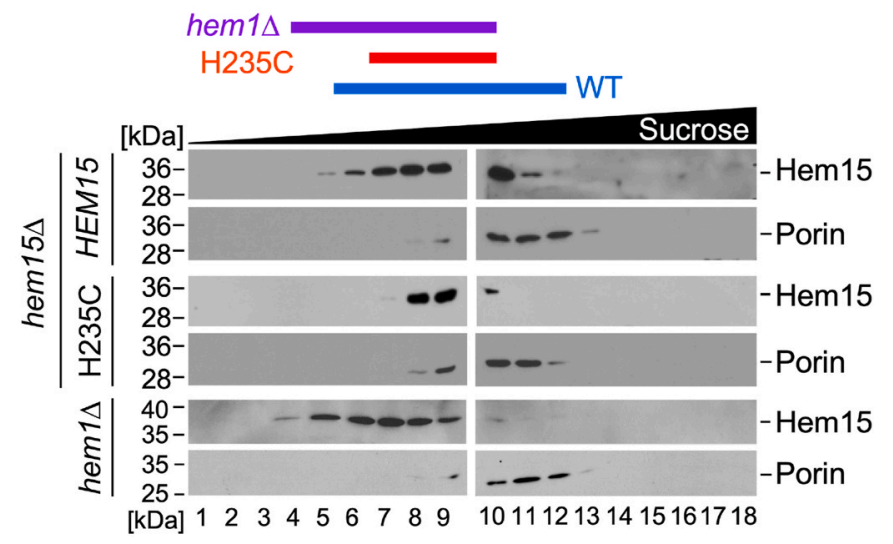

Fig. 1. Functional Hem15 forms a highmass complex. (A) Isolated mitochondria (15 $\mu \mathrm{g}$ total protein) from wild type (WT) and hem15s cells overexpressing Hem15 (from the HEM15 promoter) or expressing a vector control were subjected to SDS-PAGE and analyzed by immunoblotting with antibodies against Hem15 and the outer mitochondrial membrane protein porin (loading control). (B) High-velocity density-gradient fractionation of digitonin-solubilized lysates from mitochondria of hem $1 \Delta$ cells or hem15 $\Delta$ cells expressing Hem15 or its H235C catalytically impaired variant, analyzed by SDSPAGE with immunoblotting for Hem 15 and porin (440-kDa molecular size reference).
A

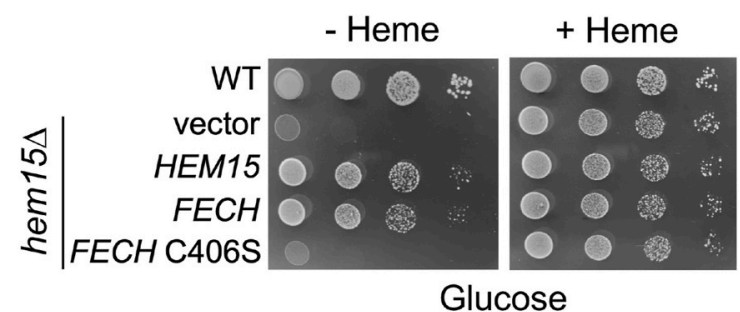

B

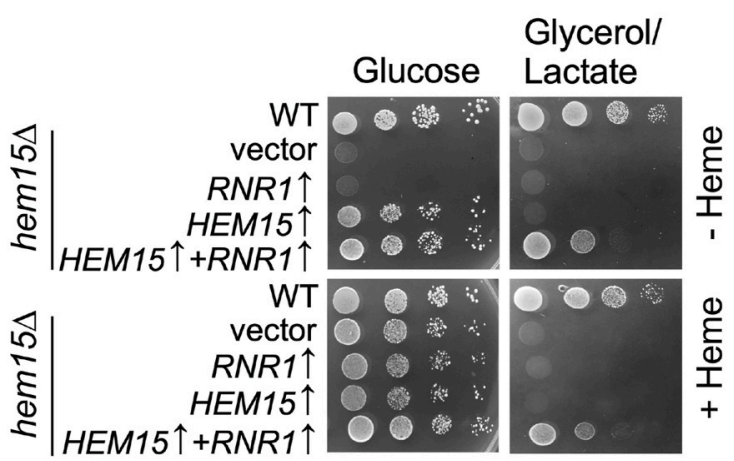

an obstacle to further in-depth functional studies of Hem15.

This inability of plasmid borne HEM15 to complement the hem15 $\Delta$ deletion mutant was hypothesized to be due to the hem15 $\Delta$ strain becoming petite, i.e., mitochondrial DNA is lost upon deletion of the HEM15 gene. Consistent with this interpretation, employing a known strategy to stabilize the mitochondrial genome resolved this obstacle. Overexpression of the dNTP checkpoint enzyme Rnr1, which encodes the large subunit of ribonucleotide reductase, has previously been very effective to stabilize mitochondrial DNA in various petite mutants via an unknown mechanism [37-39]. Employing this strategy in hem15 $\Delta$ cells following Hem15 re-expression using a YEp vector under the control of its native promoter (HEM15 $\uparrow$ ) or a constitutive, high-efficiency MET25

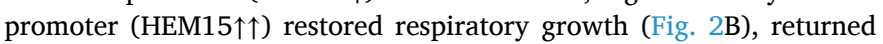
both respiratory complexes and their subunit proteins to WT levels, and permitted complementation with human FECH (Fig. 2C; Supplementary Fig. S2).
Fig. 2. Human ferrochelatase is fully functional in yeast, and loss of Hem15 results in a petite-inducing phenotype that can be reversed by overexpression of ribonucleotide reductase. (A) Hemedependent growth test of WT cells and hem15s cells expressing vector control (vector), yeast ferrochelatase (HEM15), human ferrochelatase $(F E C H)$, or the C406S variant of human ferrochelatase (FECH C406S). Cells were spotted onto SC medium with (+Heme) or without (- Heme) $20 \mu \mathrm{M}$ hemin and cultured for 2 days at $28^{\circ} \mathrm{C}$. (B) Heme-dependent fermentative and respiratory growth test of WT cells or hem $15 \Delta$ cells expressing vector control (vector), Rnr1 (RNR1 $\uparrow$ ), Hem15 under control of its native promoter (HEM15 $\uparrow$ ), or co-expressing Rnr1 and Hem15. Cells were spotted onto SC media with or without $20 \mu \mathrm{M}$ hemin and cultured for 2 days (glucose) or 5 days (glycerol/lactate) at $28^{\circ} \mathrm{C}$. (C) SDS-PAGE immunoblot showing steady-state levels of three proteins encoded by the mitochondrial genome (Cox1, Cox2, and Cox3) with aconitase loading control (Aco1), in mitochondria from cells described in panel $\mathrm{B}$.

\subsection{Hem15 is physically associated with MICOS machinery}

Protein interaction partners of Hem 15 were determined by immunoprecipitation (IP) of a FLAG-tagged Hem15 construct. Since attachment of a C-terminal tag to FECH results in an inactive enzyme [40], Hem15 was tagged immediately after its $N$-terminal mitochondrial targeting sequence, so that the natural proteolytic removal of the targeting sequence upon mitochondrial import results in a protein bearing the FLAG tag on the structurally disordered amino terminus (Supplementary Fig. S3A). This Hem15-iFLAG construct is stably expressed and functional (Supplementary Figs. S3B and S3C) and was therefore used for IP experiments.

Clarified mitochondrial lysates from hem15 $\Delta$ cells stabilized with Rnr1 and expressing Hem15-iFLAG were incubated with anti-FLAG affinity resin, and affinity-purified proteins were analyzed by LC-MS/MS to identify co-purifying proteins. In addition to Hem 15 and some of its previously known binding partners such as Ppox (Hem14) [17], the IM 
GTPase Mgm1 and five of the eight known subunits of the MICOS complex (Mic60, Mic19, Mic26, Mic27, and Mic12) were all identified as physically interacting with Hem15 (Fig. 3A). Consistent with these findings, targeted co-IP experiments showed the core MICOS subunit Mic60 co-purifies with Hem15-iFLAG (Fig. 3B), further suggesting physical association between Hem15 and MICOS. These findings are consistent with interactions observed in IP experiments with yeast MICOS [41] and human FECH [17,19].

To examine the functional significance of this Hem15-MICOS association, the impact of MIC60 deletion on Hem15 was experimentally determined. Steady-state levels of Hem15 were not affected in the mic60 $\Delta$ deletion mutant (Supplementary Fig. S3D). However, the sucrose gradient migration profile of the Hem15 high-mass complex derived from mic60 $\Delta$ mutant mitochondria was altered, indicating a shift toward smaller complex size (Fig. 3C). This shift in Hem15 oligomer fractionation pattern is similar to that observed for both the nonfunctional H235C Hem15 variant and WT Hem15 in the hem1s mutant (Fig. 1B). Collectively, these results suggest that Hem15 associates with the MICOS complex and Hem15 oligomerization is impaired in the absence of MICOS.

\subsection{MICOS facilitates proper heme biosynthetic activity of Hem15}

Respiratory growth in the absence of Mic60 was observed to be slightly impaired, and this growth defect enhanced markedly when Hem15 levels were elevated by overexpression from a plasmid (Fig. 4A). This result was observed for mic60 $\Delta$ strains in both the W303 and BY4741 genetic backgrounds and with plasmids expressing Hem15 from either its native promoter or a strong heterologous promoter. Hem15 protein levels remained similar in the presence versus the absence of Mic60 (Fig. 4B), ruling out reduced levels of Hem15 as a possible cause for the growth defect. Therefore, the activity of that Hem15 protein was examined.

WT and mic60 0 cell lysates do not have significantly different levels of Fech activity, and overexpression of Hem 15 in each cell type results in significantly increased PPIX metalation by Hem15 (Fig. 4C). Strikingly, when Hem15 is overexpressed, mic60 cells have dramatically lower Fech activity than WT cells, suggesting an inability to maximize heme production in the absence of Mic60 despite abundant Hem15 protein (Fig. 4B and C). This apparent defect in Hem 15 activity in the absence of Mic60 raises questions about the role of MICOS in the function of Hem15, which were pursued next.
A

\begin{tabular}{c|c}
$\begin{array}{c}\text { Identified } \\
\text { ORFs }\end{array}$ & $\begin{array}{c}\text { Unique Peptide } \\
\text { Sequences }\end{array}$ \\
\hline Hem15 & 15 \\
Mic60 & 59 \\
Mic19 & 18 \\
Mic26 & 10 \\
Mic27 & 8 \\
Mic12 & 6 \\
Mgm1 & 14
\end{tabular}

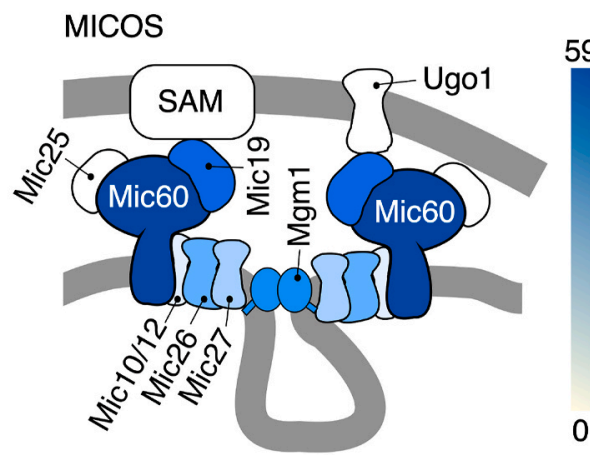

Fig. 3. Hem15 physically interacts with MICOS. (A) Table and schematic summarizing LC-MS/MS identification of immunoprecipitated proteins from mitochondrial lysates of hem15 cells expressing Hem15-iFLAG. Identified components of the MICOS machinery are color-coded to reflect the abundance of peptides corresponding to each identified subunit. Table shows representative data of two independent biological replicates. (B) Coimmunoprecipitation of Hem15-iFLAG and the endogenous Mic60 core subunit of MICOS. Digitonin-solubilized mitochondrial lysates from hem15 cells expressing Rnr1 and co-expressing either Hem15-iFLAG or empty vector control were incubated with anti-FLAG affinity resin; following the incubation, samples were subjected to SDSPAGE and analyzed by immunoblotting with indicated antibodies. The blots show $10 \%$ of mitochondrial lysate fractions before (Load, Pre) and after (Load, Post) pre-clearance with IgG agarose beads, the unbound fraction after incubation with antiFLAG affinity resin (Unbound), the whole precipitated fraction from the final wash (Wash), and half of the eluted fraction (Bound). (C) Sucrose density gradient ultracentrifugation of digitonin-solubilized Hem15 complexes from mitochondria of WT and mic60 $\Delta$ cells, analyzed as in Fig. 1B. Asterisk marks nonspecific bands. (For interpretation of the references to color in this figure legend, the reader is referred to the Web version of this article.)

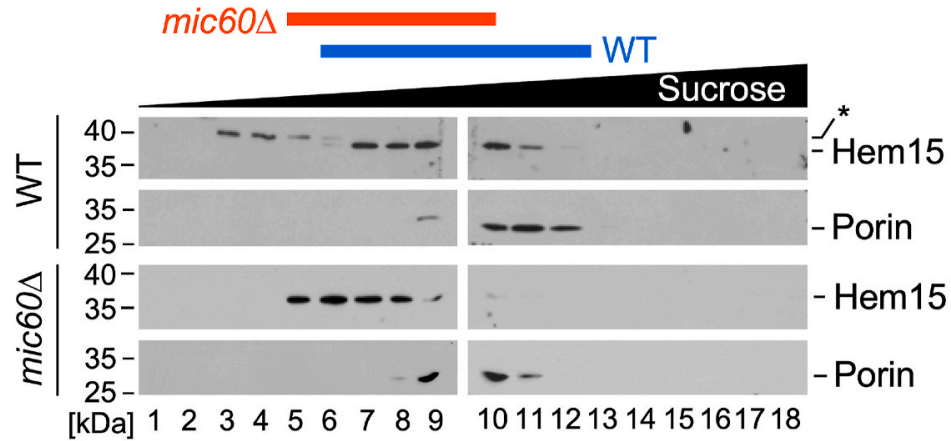


A
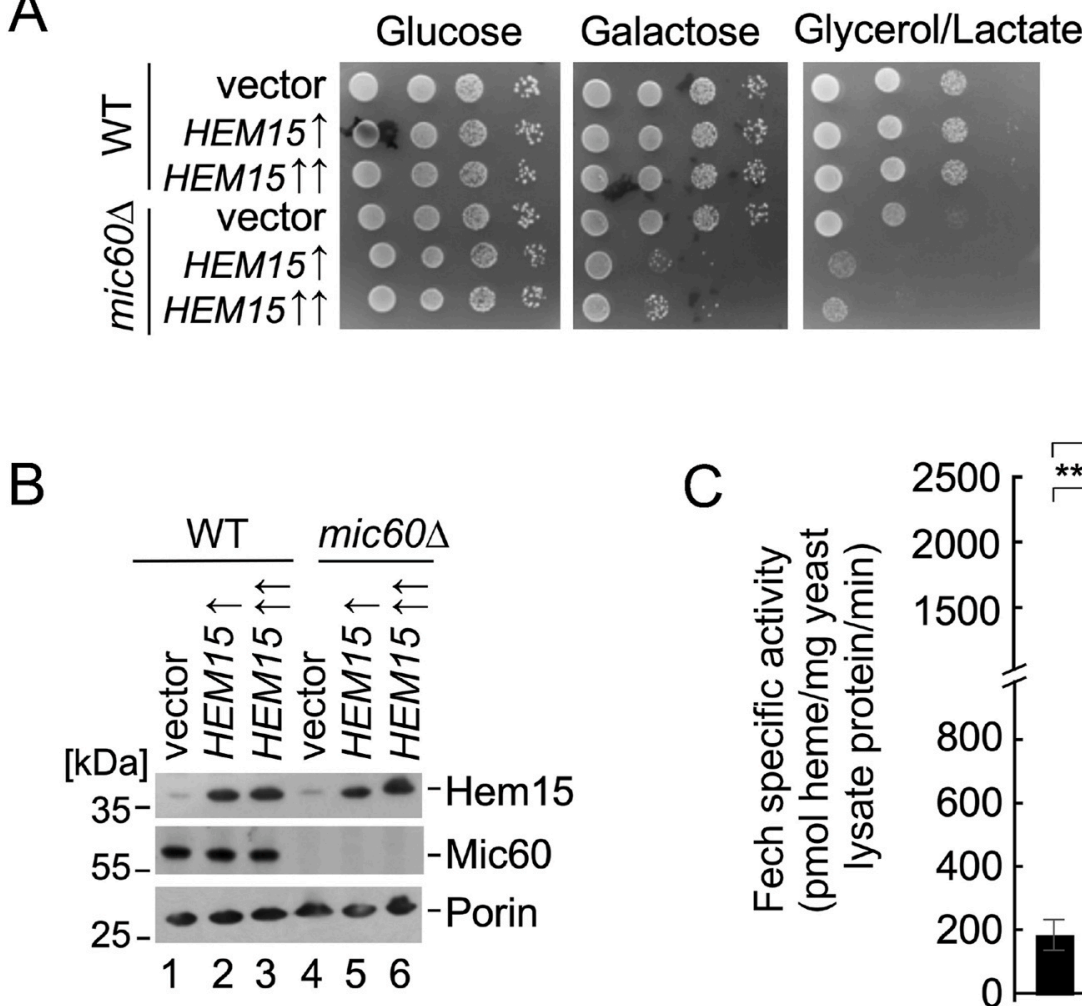

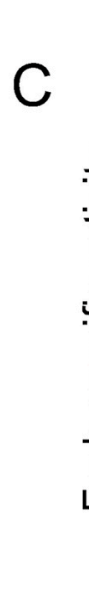

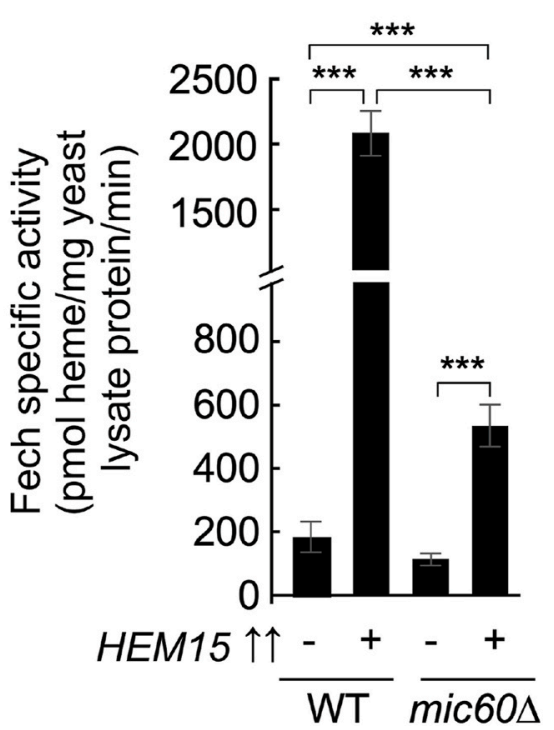

Fig. 4. Hem15 activity is impaired in the absence of MICOS. (A) Fermentative and respiratory growth of WT and mic60 $\Delta$ cells expressing vector control or Hem15 under control of its native promoter (HEM15 $\uparrow$ ) or the heterologous MET25 promoter (HEM15 $\uparrow \uparrow)$. Cells were spotted onto SC media and cultured for 2 days (glucose), 3 days (galactose), or 5 days (glycerol/lactate) at $28^{\circ} \mathrm{C}$. (B) SDS-PAGE immunoblot of indicated proteins in mitochondria from cells described in panel A. (C) Ferrochelatase specific activity in mitochondrial lysates from indicated cells. Bars indicate the average and S.D. (error bars) of 3 biological replicates. Asterisks indicate a statistically significant difference by $t$-test $(* * * \mathrm{p}<0.001)$.

\subsection{MICOS is required for optimal porphyrin substrate delivery to Hem15}

MICOS could potentially impact Hem15 activity either directly or indirectly. MICOS could be directly responsible for substrate import into or heme export out of mitochondria due to its key role in maintenance of IM-OM contact sites [24,25], which are postulated to facilitate bidirectional transport of hydrophobic molecules (e.g., phosphatidic acid and coenzyme $Q$ biosynthetic intermediates) [26,27]. Alternatively, the disorganization of the IM stemming from loss of MICOS could negatively impact mitochondrial carrier proteins required for import of substrates or export of heme, thus indirectly impacting Hem 15.

In either the direct or indirect involvement scenario, 1) impaired heme export due to the absence of MICOS might lead to mitochondrial heme build-up and inhibition of Hem15 by heme [42], since heme dissociation from Fech is the rate-limiting step in catalysis [43], or 2) impaired import of substrates and intermediates required for heme synthesis into mitochondria might limit substrate availability to Fech. To investigate these two potential mechanisms for how the MICOS machinery contributes to Fech activity, experiments were carried out to assess rates of heme transport across the IM, cellular heme levels, mitochondrial iron levels, and cellular levels of porphyrin biosynthetic precursors to heme, including PPIX.

To investigate the possibility that loss of MICOS impairs heme export, both rates of heme transport across the IM and cellular heme levels were determined. A high-affinity, genetically encoded heme sensor (HS1) $[44,45]$ was employed in an assay to compare rates of heme transport across the IM in WT and mic60 $\Delta$ cells. In this assay, heme synthesis is blocked with succinylacetone, an inhibitor of the heme synthetic enzyme Pbgs, and then reinitiated by removing the inhibitor from the medium. The heme occupancy of mitochondrial matrix- and cytosol-targeted HS1 is then monitored as a function of time [46]. In principle, the rates of heme binding to the sensor reflect the relative rates of heme trafficking from the matrix side of the mitochondrial IM (where the active site of Fech is located) to the locale of HS1. This assay revealed that hemylation rates of cytosol- and mitochondrial matrix-targeted HS1 in the mic60 $\Delta$ mutant were comparable to those seen in WT cells, indicating that there is no significant dependence of heme export on MICOS, either directly or indirectly (Fig. 5A). Consistent with this finding, total heme levels measured by UPLC were not significantly different in the presence versus the absence of Mic60 (Fig. 5B).

To investigate the possibility that loss of MICOS impairs the import of substrates of either Hem15 or other enzymes in the heme biosynthetic pathway, levels of mitochondrial iron and cellular porphyrins were measured. The iron content measured by ICP-MS was comparable in highly purified mitochondrial fractions from WT and mic60 $\Delta$ cells with or without Hem15 overexpression (Supplementary Fig. S4A), ruling out iron deficiency as the reason for reduced Fech activity in the Hem15overexpressing mic60 $\Delta$ mutant. In agreement with this result, the steady-state levels of the mitochondrial iron transporter Mrs3 were also unchanged by the absence of Mic60 (Supplementary Fig. S4B). Likewise, loss of Mic60 had no appreciable effect on the activity of the iron-sulfur cluster-containing enzyme succinate dehydrogenase, indicating that iron-sulfur cluster biogenesis is not affected (Supplementary Fig. S4C).

To test the availability of the other substrate for Fech, PPIX, and intermediates necessary for its synthesis, cellular porphyrin content was analyzed in cells lacking Mic60. Spectroscopy revealed that total porphyrin fluorescence is increased in mic60 $\Delta$ cells compared to WT (Supplementary Fig. S4D). UPLC was then employed to separate porphyrins to determine which types were causing this elevated fluorescence. The porphyrins analyzed are the oxidized products of the pathway intermediates, which are porphyrinogens. This detailed porphyrin profiling revealed a $\sim 3$-fold increase in total intermediate porphyrins in mic60 $\Delta$ cells compared to WT cells (Fig. 5C) and showed that the proportions of the 8-, 7-, 6-, 5-, and 4-COOH porphyrins were 
A

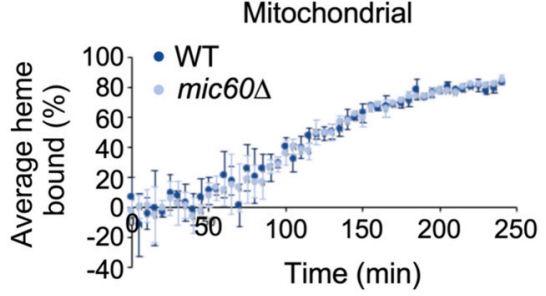

Cytosolic

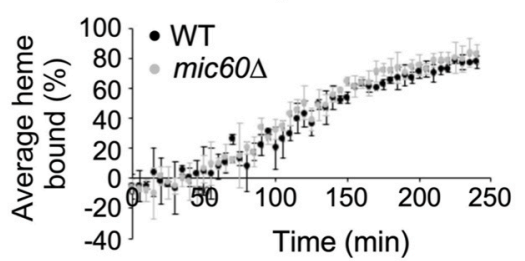

$\mathrm{B}$

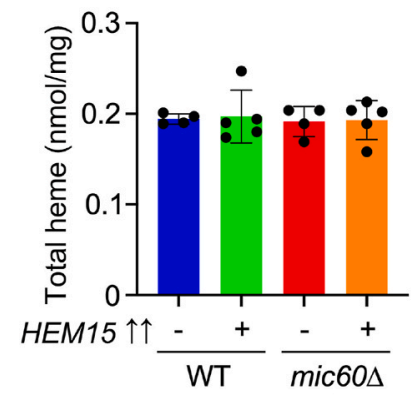

C

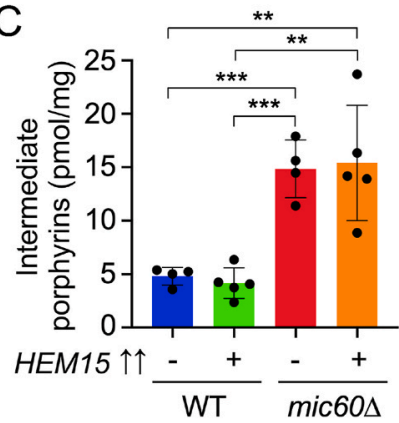

D

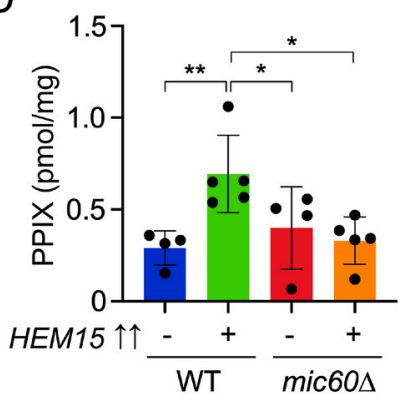

Fig. 5. MICOS-deficient cells accumulate reactive porphyrin biosynthetic precursors. (A) Relative rates of heme binding to the HS1 heme sensor in the mitochondrial matrix (left) and cytosol (right), the latter of which requires heme export across the IM, upon re-initiation of heme synthesis in WT and mic60 6 cells. Heme trafficking kinetics data shown represent mean \pm S.D. of independent triplicate cultures. (B-D) Heme, intermediate (8-, 7-, 6-, 5-, and 4- $\mathrm{COOH})$ porphyrins, and protoporphyrin IX (PPIX) levels in WT and mic60 cells with and without Hem15 overexpression, analyzed by UPLC. Bars indicate average \pm S.D. (error bars) of 4-5 biological replicates measured in technical triplicates. Asterisks indicate a statistically significant difference by $t$-test $\left(* \mathrm{p}<0.05, * * \mathrm{p}<0.01,{ }^{* * *} \mathrm{p}<0.001\right)$. altered in these cells (Supplementary Fig. S5). To rule out the possibility that metabolite transport is universally defective in mic60 $\Delta$ cells, mitochondrial lipoylation was measured in WT and mic60 $\Delta$ cells. Levels of the lipoylated mitochondrial pyruvate dehydrogenase subunit dihydrolipoamide acetyltransferase and dihydrolipoyl succinyltransferase were found to be normal in the absence of Mic60, suggesting IM carrier proteins remain generally functional and the elevated porphyrins observed in the absence of Mic60 are the result of a specific effect (Supplementary Fig. S4E).

Interestingly, PPIX was decreased in mic60 $\Delta$ cells overexpressing Hem15 compared to WT cells overexpressing Hem15 (Fig. 5D), suggesting substrate availability may be a factor that limits Fech activity in these cells. Much like the subtle growth defect and statistically insignificant decrease in Fech activity seen in mic60 $\Delta$ cells compared to WT cells with endogenous Hem15 levels (Fig. 4), levels of PPIX are not significantly different in the presence versus the absence of Mic60 when Hem15 is present at endogenous levels (Fig. 5D). However, when Hem15 is overexpressed, the growth defect becomes marked, the decrease in Fech activity becomes dramatic, and the decrease in levels of PPIX becomes significant. These three experiments suggest a role for MICOS in Hem 15 activity that is more apparent under conditions of high Hem15 levels, when PPIX may become limiting for Hem15 activity.

\subsection{MICOS-deficient cells expressing Hem15 have oxidative stress, which can be partially mitigated by synthetic restoration of IM/OM contact sites}

Since heme synthesis pathway intermediates like those elevated in the absence of Mic60 are known to be toxic, in part due to their inherent redox reactivity [5,47-49], signs of oxidative damage and stress were evaluated in the absence of Mic60. The metabolic enzyme aconitase was assessed first because of its sensitivity to damage by superoxide. While steady-state levels of aconitase were the same in WT and mic60 $\Delta$ cells overexpressing Hem15 (Fig. S6), the cells lacking Mic60 exhibited a significant decrease in aconitase specific activity, consistent with oxidative damage (Fig. 6A). Furthermore, mic60 $\Delta$ cells overexpressing Hem15 were significantly less tolerant to acute oxidative insults than WT cells overexpressing Hem15 (Fig. 6B). Consistent with these observations of oxidative stress, supplementation with the antioxidant $\mathrm{N}$-acetylcysteine partially rescued a growth defect of Hem15-overexpressing mic60 $\Delta$ cells on galactose medium (Fig. 6C).

To test whether restoring intermembrane connectivity in MICOS- deficient cells could mitigate some of these cytotoxic effects, an artificial IM-OM tether, mitoT, was generated [50] (Fig. 6D and E). This chimeric protein comprises the $\mathrm{N}$-terminal portion of the IM protein Sco2 (residues 1-112) encompassing the mitochondrial targeting sequence and transmembrane domain, followed by a short (12 amino acid residues) unstructured linker derived from the $E$. coli LacI protein, a transmembrane helix of the OM import receptor protein Tom20 (residues 1-20), and the GFP moiety. The optimal length of the linker region was deduced from the previously reported analogous construct [26].

Co-expression of mitoT in Hem15-overexpressing mic60s cells improved growth on galactose and glycerol-lactate media, reflecting a partial rescue effect (Fig. 6F). Interestingly, mitoT expression had the opposite effect in Hem15-overexpressing WT cells, suggesting that excess intermembrane tethering has a negative effect on the normal function of mitochondria. MitoT expression also resulted in increased steady-state levels of Hem15 protein in both WT and mic60 cells (Fig. 6E) although the reason for this effect is unclear at present. The rescue appears to be due to a remarkable increase in oxidative stress tolerance in the Hem15-overexpressing mic60s cells co-expressing mitoT (Fig. 6G).

\section{Discussion}

Towards the goal of better understanding the molecular and functional organization of yeast ferrochelatase (Hem15) and, more broadly, the regulation of the heme biosynthetic pathway, this study has revealed several new findings.

The functional state of Hem 15 was assessed and the yeast enzyme compared to human ferrochelatase. Hem15 assembles into a high-mass oligomer, which likely represents the functional enzyme, as it is compromised both in hem $1 \Delta$ cells blocked at a very early stage of heme biosynthesis and in cells expressing the catalytically inactive $\mathrm{H} 235 \mathrm{C}$ Hem15 mutant. This study confirmed that the yeast $\mathrm{H} 235$ residue is critical for Fech activity in yeast, much like the homologous H263 residue in humans [31], and is similarly hypothesized to be critical for proton abstraction from PPIX for metalation and heme formation.

To determine how the active-site structure of Hem15 is impacted by the $\mathrm{H} 235 \mathrm{C}$ mutation, the $\mathrm{H} 235 \mathrm{C}$ variant was crystallized and its structure solved at $2.4 \AA$ resolution. This structure reveals that the location and orientation of active-site residues in the WT protein and $\mathrm{H} 235 \mathrm{C}$ Hem15 variant are similar, as are the active-site hydrogen-bonding 

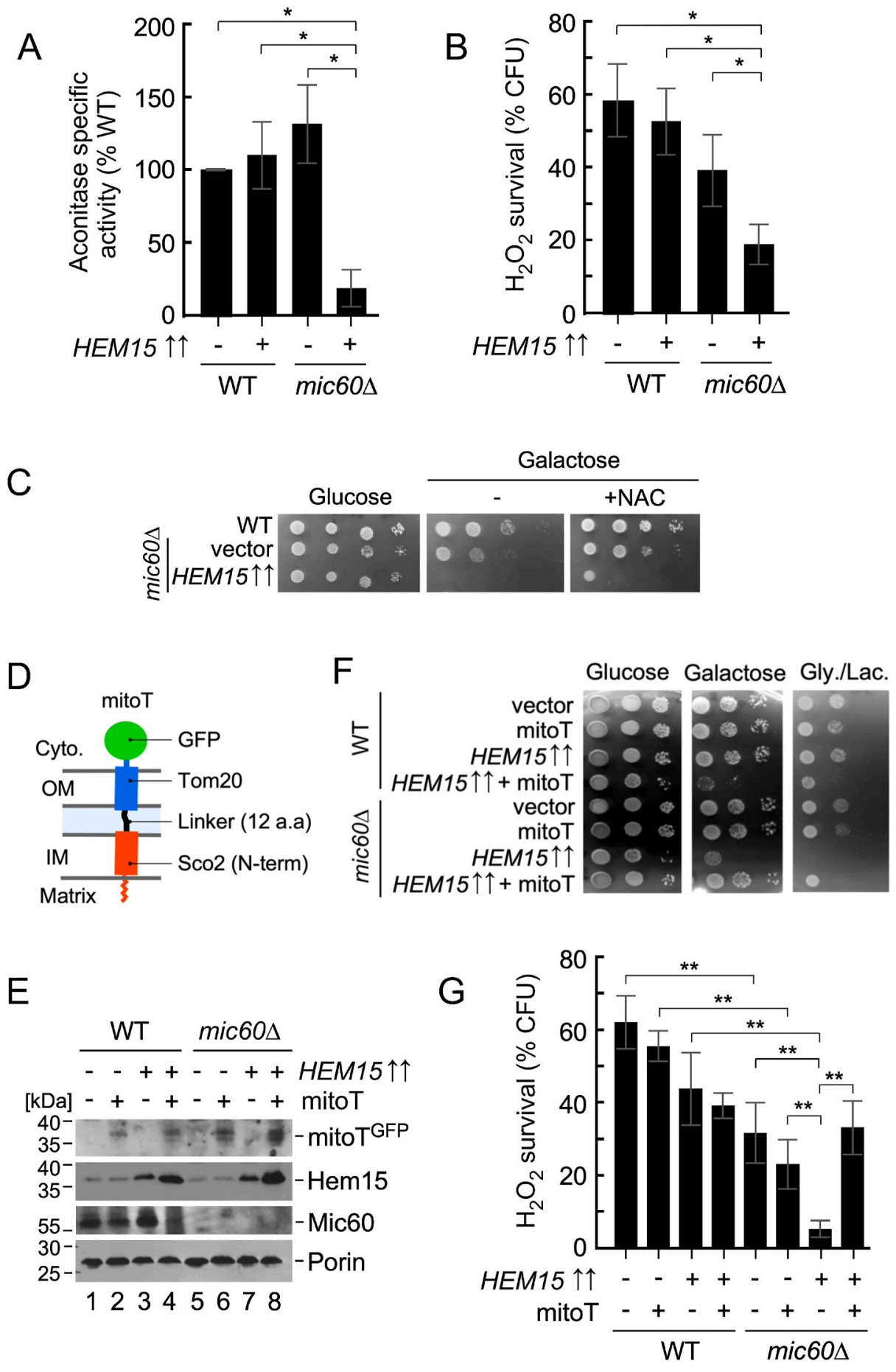

Fig. 6. MICOS-deficient cells expressing Hem15 exhibit oxidative stress that can be mitigated by a synthetic intermembrane bridge. (A) Aconitase enzymatic activity in mitochondria isolated from WT and mic60s cells with and without Hem15 overexpression, harvested after 5 days in culture. Bars indicate the average \pm S.D. (error bars) of 3 biological replicates. Asterisks indicate a statistically significant difference by one-way ANOVA with Tukey's post-hoc test (*p $<0.05$ ). (B) Hydrogen peroxide sensitivity of cells described in panel A. Cells were cultured to mid-log phase, normalized, and acutely treated with $1 \mathrm{mM}$ hydrogen peroxide for $1 \mathrm{~h}$ at $28^{\circ} \mathrm{C}$. Following treatment, cultures were diluted to 300 cells per sample and plated to assess viable colony forming units after $48 \mathrm{~h}$ of growth at $28^{\circ} \mathrm{C}$. Bars indicate the average \pm S.D. (error bars) of 4 biological replicates. Asterisks indicate a statistically significant difference by one-way ANOVA with Tukey's posthoc test ("p $<0.05$ ). (C) Growth test of cells described in panel A with or without the addition of $10 \mathrm{mM} N$-acetylcysteine (NAC), assessed as in Fig. 4A. (D) Schematic depicting mitoT synthetic intermembrane tether. (E) SDS-PAGE immunoblot analysis of mitochondria isolated from WT and mic60 $\Delta$ cells expressing vector controls, overexpressing Hem15 or mitoT, or overexpressing both constructs simultaneously. Steady-state levels of indicated proteins were visualized with appropriate antibodies (anti-GFP antibody was used to detect mitoT). The outer mitochondrial membrane protein porin served as a loading control. (F) Growth test of cells described in panel E, assessed as in Fig. 4A. (G) Hydrogen peroxide sensitivity of cells described in panel E, handled and analyzed as in panel B. networks (Supplementary Fig. S1E). This intact network differs from the human H263C variant structure where the network is disrupted [31]. It is unclear why this difference between the yeast and human catalytic mutants exists, though both variants are inactive due to the absence of the base (H235 in yeast and H263 in humans) necessary for proton abstraction.

Human FECH is able to efficiently replace the yeast enzyme, despite the human enzyme requiring a [2Fe-2S] cluster for enzyme activity [32-34] that is absent in the yeast enzyme. This iron-sulfur cluster is believed to serve as a sensor for the redox state and/or $\mathrm{pH}$ of the mitochondrial matrix [32,51]. The finding that WT human FECH, but not a mutant bearing the C406S substitution for one of the cluster-binding ligands, complements the yeast deletion mutant suggests that the cluster is successfully formed in the context of yeast mitochondria.

Hem15-deficient cells exhibit a petite-inducing phenotype that can be rescued genetically through re-expression of Hem15 in conjunction with overexpression of ribonucleotide reductase subunit Rnr1, a genetic manipulation known to stabilize mitochondrial DNA in petite mutants [39,52]. This finding explains previously described difficulties in establishing a robust genetic complementation of the hem15 15 mutant with plasmid-borne Hem15 [36]. While the exact molecular underpinnings of the petite-inducing phenotype of hem $15 \Delta$ are currently unclear, they might arise from impaired hemylation of mitochondrial 
matrix hemoproteins with connections to the mitochondrial genome, such as the yeast flavohemoglobin Yhb1 or translational activator Mss51 [53-56]. Further studies are warranted to explore the connection between loss of Hem15 and instability of mitochondrial DNA.

The high-mass Hem 15 complex was found by proteomic analysis to contain components of the MICOS machinery. A portion of the core MICOS subunit Mic60 is exposed to the matrix side of the IM [24,25] and is thus likely to mediate this Hem15-MICOS association. Loss of Mic60 affects the high-mass oligomeric species of Hem15 akin to the destabilizing effect of the catalytic H235C Hem 15 variant and the Alas (Hem1) deletion mutant, consistent with the idea that MICOS contributes to the molecular organization of Fech. These results agree with earlier reports suggesting that mammalian FECH is a component of a large complex termed the mitochondrial heme metabolon [17-19]. Studies in mammalian cells have shown the heme metabolon contains components of MICOS, underscoring the conservation and importance of this connection.

The yeast MICOS presents as a series of large oligomers [41] and, since Mic60 is about 1.5-fold more abundant than Hem15 [30,57], it is unlikely that its subunits form stable stoichiometric complexes with Hem15. Instead, there may be a dynamic association between Hem15 and MICOS that is not essential for Hem15 activity but is nevertheless important for its ideal performance. In agreement with this idea is the observation that basal Hem 15 activity is not significantly affected in the mic $60 \Delta$ mutant, whereas the added strain caused by overexpression of Hem15 results in a profound respiratory growth defect, reduces levels of PPIX, attenuates Hem15 activity, elevates levels of intermediate porphyrins, and results in oxidative damage and stress, compared to similarly treated WT cells. Porphyrin profiling under these conditions revealed that the levels of some porphyrins like coproporphyrins and PPIX are decreased in the absence of Mic60, while others like hexacarboxylporphyrins and heptacarboxylporphyrins are increased. Low PPIX levels could be attributed to reduced Ppox activity, a downstream effect of low Cpox activity since Cpox is inhibited by heme [58], or a more complex result of this apparent disruption of porphyrin transport and homeostasis. The elevated intermediate porphyrins are likely causing the oxidative damage and stress observed when Hem15 is overexpressed.

These results suggest the FECH-MICOS association has functional significance. We propose a model wherein IM-OM contact sites formed by MICOS facilitate the transfer of intermediate porphyrinogen precursors across the mitochondrial membranes, thereby ensuring optimal substrate delivery to Fech as well as PPOX (Fig. 7). Data in the current study do not exclude the possibility that MICOS is directly involved in this transport of heme biosynthetic intermediates, analogous to its proposed role in transporting phospholipids such as phosphatidic acid [26] and coenzyme Q biosynthetic intermediates [27]. However, it may be more likely that MICOS plays an indirect role through one or more plausible mechanisms. For instance, the complex may aid the heme intermediate transport process through bridging the OM and IM to create a proximity conduit between these membranes, as suggested by the rescue of oxidative stress tolerance seen in Hem15-overexpressing mic $60 \Delta$ cells co-expressing a synthetic mitoT [50] tether. In mammalian cells, MICOS might be required for spatial organization of the currently elusive coproporphyrinogen III and protoporphyrinogen IX transporters in the OM and IM, respectively, thus accounting for the accumulation of tetrapyrrole intermediates arising from cellular accumulation of the heme synthesis intermediates during uroporphyrinogen III decarboxylation in MICOS-deficient cells (Fig. 5C and Supplementary Fig. S5). It is unclear under which conditions MICOS and Fech physically interact, but this interaction is expected to be dynamic and transient, as discussed above.

Intriguingly, Mic60 is highly conserved with homologs found in $\alpha$-proteobacteria, wherein the gene clusters with heme biosynthetic genes [59,60], further supporting a potential functional link between MICOS and the heme biosynthetic pathway. The additional identification of the conserved dynamin-like GTPase Mgm1 (OPA1 in humans) as a potential interacting partner of Fech supports earlier proteomic studies in mammalian mitochondria $[17,19]$. Our recent study established that the $m g m 1 \Delta$ mutant exhibits a marked defect in nuclear heme levels [46], further supporting a model in which IM ultrastructure-related factors like Mgm1 and MICOS may cooperate with Fech to facilitate delivery of its substrate and/or distribution of its product.

\section{Materials and Methods}

\subsection{Yeast strains, plasmids, and growth conditions -}

Yeast strains used in this work were of the W303-1B genetic background (MAT $\alpha$ ade2-1 can1-100 his3-11,15 leu2-3 trp1-1 ura3-1), unless specified otherwise. The $\triangle$ MICOS strain included in a Supplementary figure lacks the genes MIC10, MIC60, MIC19, MIC27, MIC26, and MIC12. Plasmids for wild-type and variant Hem15 and human ferrochelatase expression in $S$. cerevisiae were produced as previously described [61,62]. The HEM15 ORF with its 350-bp native promoter region was subcloned into pRS424 and pRS426 vectors from the pRS316-Hem15 plasmid described before [61]. This plasmid also served as a template to generate a pRS426-Hem 15 vector in which the HEM15 ORF is under the control of the heterologous MET25 promoter.

\section{Wild type}

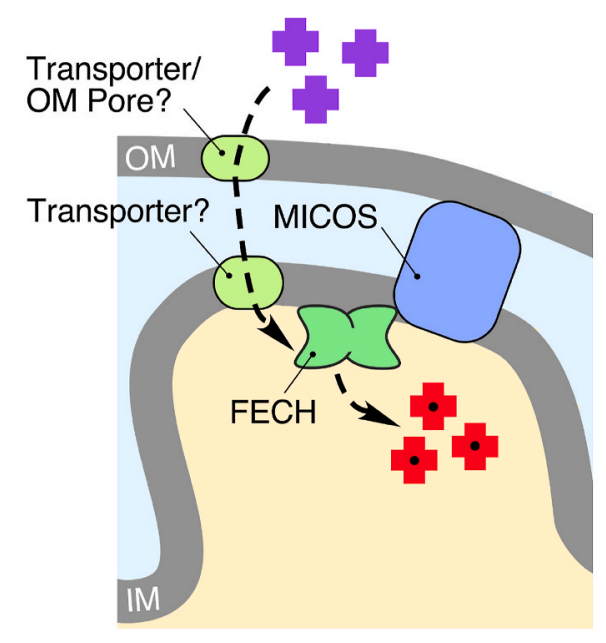

\section{$\operatorname{mic} 60 \Delta$}

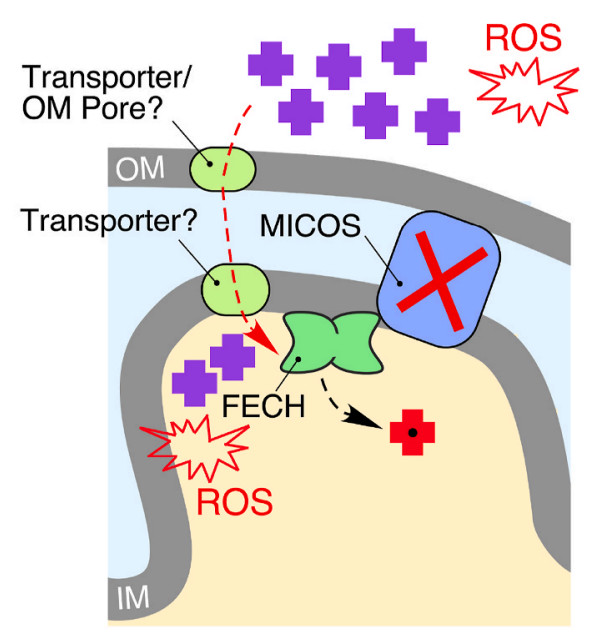

Fig. 7. Model for involvement of MICOS in heme biosynthesis. IM-OM contacts formed by MICOS may facilitate the transfer of intermediate porphyrin precursors (purple crosses) across the mitochondrial membranes into the matrix, thus ensuring optimal delivery of substrate to Fech for synthesis of heme (red crosses). Loss of Mic60/MICOS results in accumulation of porphyrin intermediates and subsequent oxidative damage. See Discussion for additional details. (For interpretation of the references to color in this figure legend, the reader is referred to the Web version of this article.) 
To generate a plasmid expressing Hem15-iFLAG, the mitochondrial targeting sequence (MTS) of Hem15 (amino acid residues 1-31) with a flanking region containing the FLAG epitope tag at the 3'-end was PCRamplified from the pRS426-Hem15 plasmid using primers 5'CGCGGATCCATGCTTTCCAGAACAATCCGTACACAAGGTTCCTTCCTAA GAAGATCACAACTGACCATT-3' and 3'-CTTGTCGTCATCGTCTTTGTAGTCCTGCATGTTGAATGTAACCGAAAATGATCTTGTAATGGTCAGTT GTGATCTTCT-5'. In a separate reaction, Hem15 excluding the MTS (amino acid residues 31-393) containing the FLAG epitope tag at the 5'end was PCR amplified from the same plasmid using primers 5'-GACTACAAAGACGATGACGACAAGAATGCACAAAAGAGATCACCCACAGGAAT TGTTTTGATGAACATGGGTGGC-3' and 3'-GCGCTCGAGTCAAGTAGATTCGTGATTGCCAAATACCAATGAAAGGTCCTTTACAGGATCATTGG ACTT-5'. Gel-purified products of the reactions described above were fused together by overlap extension PCR using 5'- CGCGGATCCATGCTTTCCAGAACAATCCGTACACAAGGTTCCTTCCTAAGAAGATCACAACTGACCATT-3' and 3'-GCGCTCGAGTCAAGTAGATTCGTGATTGCC AAATACCAATGAAAGGTCCTTTACAGGATCATTGGACTT-5, including 5'-BamHI and 3'-XhoI restriction sites, respectively. The obtained product was cloned into pRS423 vector under the control of the MET25 promoter and $C Y C 1$ terminator.

The pRS424-Rnr1 plasmid was generated by subcloning a 2.8-kbp fragment from the YEplac181-Rnr1 vector [39]. The pCM185-Mrs3-FLAG plasmid has been described previously [63]. All plasmids were validated by DNA sequencing.

Depending on experiment, cells were cultured in yeast extractpeptone (YP) or synthetic complete (SC) media lacking nutrients (amino acids or nucleotides) necessary to maintain plasmid selective pressure [64] containing either $2 \%$ glucose, $2 \%$ galactose, or $2 \%$ glycerol $/ 2 \%$ lactic acid mix as the carbon source. To culture heme synthesis-deficient strains, cells were grown in the presence of either hemin or Tween-80/ergosterol/methionine mix as described previously $[65,66]$. Growth tests to assess respiratory capacity and quantify hydrogen peroxide sensitivity were carried out as before $[67,68]$, except cells lacking functional Hem 15 were cultured in $20 \mu \mathrm{M}$ hemin. Cultures used for growth tests were grown overnight (or two days in the case of cells lacking functional Hem15) in SC media lacking relevant nutrients to maintain plasmid selection then normalized to $\mathrm{OD}_{600}$ of 1 and spotted onto SC plates with or without $20 \mu \mathrm{M}$ hemin.

\subsection{Heme and porphyrin analysis -}

Total cellular porphyrin content was measured using a previously described porphyrin fluorescence assay [44]. Briefly, $1 \times 10^{8} \log$-phase cells were harvested, washed in sterile ultrapure water, resuspended in $500 \mu \mathrm{L}$ of $20 \mathrm{mM}$ oxalic acid and stored at $4^{\circ} \mathrm{C}$ overnight $(16-18 \mathrm{~h})$ in the dark. The next day, $500 \mu \mathrm{L}$ of $2 \mathrm{M}$ oxalic acid was added to the cell suspensions. Half the cell suspension was transferred to a heat block set at $95^{\circ} \mathrm{C}$ and heated for $30 \mathrm{~min}$ to demetallate the heme iron to yield fluorescent protoporphyrin IX. The other half of the cell suspension was kept at room temperature for $30 \mathrm{~min}$. All suspensions were centrifuged for $2 \mathrm{~min}$ on a table-top microfuge at $21,000 \times g$ and the porphyrin fluorescence spectra (excitation at $400 \mathrm{~nm}$ ) or emission at $620 \mathrm{~nm}$ of $200 \mu \mathrm{L}$ of each sample was recorded on a Synergy Mx multi-modal plate reader using black Greiner Bio-one flat bottom fluorescence plates. The "boiled" sample provides a measure of total heme and protoporphyrin IX in cells. The "room temperature" sample provides a measure of total protoporphyrin IX in cells. When the "room temperature" sample is subtracted from the "boiled" sample, "total" cellular heme is revealed. Concentrations of heme or protoporphyrin IX are derived from standard curves of known concentrations of heme boiled in oxalic acid similarly to the description above.

For high-resolution heme and porphyrin analysis, yeast cultures $(125 \mathrm{~mL})$ were inoculated from a fresh culture at $\mathrm{OD}_{600 \mathrm{~nm}}$ of 0.003-0.009 and grown overnight at $37^{\circ} \mathrm{C}$ and $225 \mathrm{rpm}$ shaking until $\mathrm{OD}_{600 \mathrm{~nm}}=1$. One hundred $\mathrm{mL}$ of culture was harvested by centrifugation at $4000 \mathrm{rpm}$ for $5 \mathrm{~min}$. Cells were then washed in $5 \mathrm{ml}$ ice cold water and re-centrifuged. Pellets were then resuspended on ice in 4 mL lysis buffer (50 mM Tris-MOPS, pH 8.0, $100 \mathrm{mM} \mathrm{KCl,} \mathrm{1 \%} \mathrm{sodium}$ cholate) with $40 \mu \mathrm{L}$ fungal protease inhibitor cocktail (Sigma P-8215) and transferred to $50-\mathrm{mL}$ conical tubes. Glass beads ( $4 \mathrm{~mL}, 0.5 \mathrm{~mm}$ ) were then added, and cells were vortexed for $1 \mathrm{~min}$ at maximum speed followed by $1 \mathrm{~min}$ on ice, repeated for a total of 5 vortex cycles. Tubes containing lysate and beads were then centrifuged at $\sim 9000 \times g$ for 5 min. Supernatant was removed using a 1-mL pipette, taking care not to disturb the pellet. The supernatant was then transferred to 2 -ml microcentrifuge tubes and further centrifuged at $15000 \times g$ for $10 \mathrm{~min}$. Supernatant was transferred to fresh microcentrifuge tubes and stored on ice for up to $2 \mathrm{~h}$ during measurements. Total protein concentration of yeast lysate was measured via a NanoDrop spectrophotometer with $1 \mathrm{~A}$ $=1 \mathrm{mg} / \mathrm{mL}$ setting. Heme and porphyrin analysis were carried out at the University of Utah Center for Iron and Heme Disorders core facility as previously described $[11,17]$.

\subsection{Hem15 activity assays -}

Lysate volumes ranging from 0 to $200 \mu \mathrm{L}$ were brought to a total volume of $850 \mu \mathrm{L}$ with lysis buffer in 3-mL glass tubes. Master mix (150 $\mu \mathrm{L}$ ) consisting of $20 \mathrm{mM}$ ferrous sulfate, $\sim 1 \mathrm{mM}$ protoporphyrin IX, and $33.3 \mathrm{mM} \beta$-mercaptoethanol was added to start the assay. Samples were incubated in the dark at $37^{\circ} \mathrm{C}$ for $15 \mathrm{~min}$. Heme produced in lysate activity assays was quantified by pyridine hemochromogen assay. To stop the assay reactions and produce the pyridine hemochrome derivative, 1 $\mathrm{mL} 50 \%(\mathrm{v} / \mathrm{v})$ pyridine: $0.2 \mathrm{~N} \mathrm{NaOH}$ solution was added to $1-\mathrm{mL}$ assay samples. Heme content was measured via differential spectra of oxidized and reduced samples as described previously [69-71].

\subsection{Variant construction, protein expression, purification, and $X$-ray crystallography -}

The Hem15 variant H235C was constructed using QuikChange sitedirected mutagenesis (Agilent) and verified by sequencing. His-tagged mature wild-type and variant Hem15 were produced as previously described [40,72]. In vivo ferrochelatase activity of the variant was assessed by complementation and rescue of a strain of Escherichia coli lacking functional ferrochelatase, $p p f C \Delta[73,74]$. The H235C variant protein was concentrated to $\sim 400 \mu \mathrm{M}$ and crystals were grown by hanging drop with mother liquor composed of $0.1 \mathrm{M}$ Bis-Tris $\mathrm{pH} 6.5$, 25\% PEG 3350 within $48 \mathrm{~h}$.

All data sets were collected at the Advanced Photon Source and SERCAT on beamline 22-ID. Phases were obtained by using a monomer of wild-type Hem15 (PDB ID 1LBQ) as a molecular replacement search model. Molecular replacement was performed using the program CNS [75]. Iterative rounds of model building and refinement were performed with the programs COOT [76] and CNS, respectively. Data collection, refinement statistic, and PDB ID for the H235C structure are listed in Table SI. Structural representations were created using PyMol [77].

\subsection{Mass spectrometry and data analysis -}

Affinity purification and mass spectrometry were carried out as described for human ferrochelatase [17], except 1\% digitonin was used to solubilize purified mitochondria. Subsequent analysis of candidate hits against the CRAPome database (www.crapome.org) eliminated known contaminants and non-specific interactors.

\subsection{Mitochondrial isolation and assays -}

Mitochondria-enriched fractions were isolated using established protocols [78]. For ICP-MS measurements, mitochondrial fractions were further purified using discontinuous $14 \% / 22 \%$ Nicodenz gradients as described [79]. Total mitochondrial protein concentrations were 
determined using the Coomassie Plus kit (Thermo Scientific). Proteins or protein complexes were separated by SDS-PAGE, blue native (BN)-PAGE, or continuous $12-50 \%$ sucrose density gradient ultracentrifugation as previously described $[67,80]$. Aconitase specific activity was determined as before [81].

\subsection{Heme trafficking dynamics assay -}

Heme trafficking rates were monitored as previously described [46]. Briefly, in this three-step assay: 1) heme synthesis is first inhibited with succinylacetone (SA) in sensor-expressing cells, 2) the block in heme synthesis is then removed by resuspending cells into media lacking SA, and 3) the time-dependent change in the heme occupancy of HS1 is monitored. The fractional heme occupancy of the sensor can be determined using previously established sensor calibration protocols [44]. The percent of sensor bound to heme (\% Bound) is calculated by determining the sensor eGFP/mKATE2 fluorescence ratio $(R)$ under a given test condition relative to the eGFP/mKATE2 fluorescence ratio when the sensor is $100 \%\left(R_{\max }\right)$ or $0 \%\left(R_{\min }\right)$ bound to heme, as described previously [44-46,82]. $R_{\min }$ is determined by measuring the HS1 eGFP/mKATE2 ratio in parallel cultures that are conditioned with succinylacetone (SA), which inhibits the second enzyme in the heme biosynthetic pathway, Pbgs [83], and $R_{\max }$ can be determined by permeabilizing cells and adding an excess of heme to saturate the sensor [44]. Given HS1 is quantitatively saturated with heme in the cytosol, nucleus, and mitochondria of WT yeast, $R_{\max }$ is typically determined by measuring the HS1 eGFP/mKATE2 ratio in parallel WT cultures grown without SA [44].

Growth for the heme trafficking dynamics assay was accomplished by culturing HS1-expressing cells with or without $500 \mu \mathrm{M}$ SA (SigmaAldrich) in SC media lacking leucine. Triplicate 5-mL cultures were seeded at an initial optical density of $\mathrm{OD}_{600 \mathrm{~nm}}=0.01-0.02\left(\sim 2-4 \times 10^{5}\right.$ cells $/ \mathrm{mL}$ ) and grown for $14-16 \mathrm{~h}$ at $30^{\circ} \mathrm{C}$ and shaking at $220 \mathrm{rpm}$ until cells reached a final density of $\mathrm{OD}_{600 \mathrm{~nm}} \sim 1.0\left(\sim 2 \times 10^{7}\right.$ cells $\left./ \mathrm{mL}\right)$. After culturing, 1 OD (or $\sim 2 \times 10^{7}$ cells) were harvested, washed twice with 1 $\mathrm{mL}$ of ultrapure water, and resuspended in $1 \mathrm{~mL}$ of fresh media. The cells that were pre-cultured without SA provided HS1 $R_{\max }$ values. The SAconditioned cells were split into two $500-\mu \mathrm{L}$ fractions. One fraction was treated with $500 \mu \mathrm{M}$ SA to give HS1 $R_{\min }$ values. The other fraction was not treated with SA so that heme synthesis could be re-initiated to give compartment-specific heme trafficking rates. HS1 fluorescence was monitored on $200 \mu \mathrm{L}$ of a $1 \mathrm{OD} / \mathrm{mL}\left(\sim 2 \times 10^{7}\right.$ cells $\left./ \mathrm{mL}\right)$ cell suspension using black Greiner Bio-one flat bottom fluorescence plates and a Synergy Mx multi-modal plate reader. Fluorescence of eGFP $\left(\lambda_{\text {exc. }}=488 \mathrm{~nm}\right.$, $\left.\lambda_{\text {em. }}=510 \mathrm{~nm}\right)$ and mKATE2 $\left(\lambda_{\text {exc. }}=588 \mathrm{~nm}, \lambda_{\text {em. }}=620 \mathrm{~nm}\right)$ was recorded every $5 \mathrm{~min}$ for $4 \mathrm{~h}$, with the plate being shaken at "mediumstrength" for $30 \mathrm{~s}$ prior to each read. Background fluorescence of cells not expressing the heme sensors was recorded and subtracted from the eGFP and mKATE2 fluorescence values.

\subsection{Immunoblotting -}

Separated proteins were transferred to either nitrocellulose or PVDF membranes, blocked in 5\% non-fat milk in PBS with $0.1 \%$ Tween- 20 and incubated with relevant primary antibodies and goat anti-mouse or goat anti-rabbit horseradish peroxidase-coupled secondary antibodies (Santa Cruz Biotechnology). Proteins of interest were visualized by incubation of membranes with chemiluminescence reagents (Thermo Scientific) and exposure to X-ray film. For assessment of Hem15 endogenous levels, proteins were detected using the Odyssey Fc imaging system (LI-COR Biosciences) and quantified using built-in Image Studio software. The following primary antibodies were used: mouse anti-porin (459500, Thermo Scientific), mouse anti-Cox1 (ab110270, Abcam), mouse antiCox2 (ab110271, Abcam), mouse anti-Cox3 (ab110259 Abcam), and mouse anti-FLAG (sc-166355, Santa Cruz Biotechnology). We also used rabbit sera against $S$. cerevisiae Hem15 (produced in the Dailey lab),
Rip1 (provided by Dr. D. Winge), Mic60 (provided by Dr. N. Pfanner), Aco1 (provided by Dr. R. Lill), and $\beta$-subunit of $F_{1}$ ATP synthase (provided by Dr. A. Tzagoloff). All antibodies were tested for reliability to ensure specificity of detection.

\section{Declaration of competing interest}

The authors declare no competing interests.

\section{Acknowledgements}

We thank Drs. Dennis Winge, Diane Ward, and John Phillips (University of Utah); Antoni Barrientos (University of Miami); Alexander Tzagoloff (Columbia University); Nikolaus Pfanner (University of Freiburg); Roland Lill (University of Marburg); and Jonathan Friedman (UT Southwestern) for reagents. We also thank Dr. Javier Seravalli and the University of Nebraska-Lincoln Redox Biology Center Biophysics Core for help with ICP-MS analyses and Hector Bergonia at the University of Utah for help with heme and porphyrin analyses.

\section{Appendix A. Supplementary data}

Supplementary data to this article can be found online at https://doi. org/10.1016/j.redox.2021.102125.

\section{Funding}

This work was supported by the National Institutes of Health grants GM108975 and GM131701-01 (O.K.), ES025661 (A.R.R.), DK111653 (A.E.M.), and DK110858-supported Pilot and Feasibility Grants through the University of Utah Center for Iron and Heme Disorders (A.E.M., A.R. R. and O.K.); and the U.S. National Science Foundation grant MCB155279 (A.R.R.).

\section{References}

[1] I. Hamza, H.A. Dailey, One ring to rule them all: trafficking of heme and heme synthesis intermediates in the metazoans, Epub 2012/05/12, Biochim. Biophys. Acta 1823 (9) (2012) 1617-1632, https://doi.org/10.1016/j.bbamcr.2012.04.009. PubMed PMID: 22575458; PMCID: PMC3412874.

[2] T.L. Poulos, Heme enzyme structure and function, Epub 2014/01/10, Chem. Rev. 114 (7) (2014) 3919-3962, https://doi.org/10.1021/cr400415k. PubMed PMID: 24400737; PMCID: PMC3981943.

[3] A.R. Reddi, I. Hamza, Heme mobilization in animals: a metallolipid's journey, Epub 2016/06/03, Acc. Chem. Res. 49 (6) (2016) 1104-1110, https://doi.org/ 10.1021/acs.accounts.5b00553. PubMed PMID: 27254265; PMCID: PMC5629413.

[4] X. Yuan, M.D. Fleming, I. Hamza, Heme transport and erythropoiesis, Epub 2013/ 02/19, Curr. Opin. Chem. Biol. 17 (2) (2013) 204-211, https://doi.org/10.1016/j. cbpa.2013.01.010. PubMed PMID: 23415705; PMCID: PMC3634864.

[5] J.D. Phillips, Heme biosynthesis and the porphyrias, Epub 2019/07/22, Mol. Genet. Metabol. 128 (3) (2019) 164-177, https://doi.org/10.1016/j. ymgme.2019.04.008. PubMed PMID: 31326287; PMCID: PMC7252266.

[6] J.M. Camadro, H. Chambon, J. Jolles, P. Labbe, Purification and properties of coproporphyrinogen oxidase from the yeast Saccharomyces cerevisiae, Epub 1986/ 05/02, Eur. J. Biochem. 156 (3) (1986) 579-587, https://doi.org/10.1111/j.14321033.1986.tb09617.x. PubMed PMID: 3516695

[7] R. Labbe-Bois, The ferrochelatase from Saccharomyces cerevisiae. Sequence, disruption, and expression of its structural gene HEM15, J. Biol. Chem. 265 (13) (1990) 7278-7283. Epub 1990/05/05. PubMed PMID: 2185242.

[8] G.H. Elder, J.O. Evans, Evidence that the coproporphyrinogen oxidase activity of rat liver is situated in the intermembrane space of mitochondria, Epub 1978/05/ 15, Biochem. J. 172 (2) (1978) 345-347, https://doi.org/10.1042/bj1720345. PubMed PMID: 666752; PMCID: PMC1185701.

[9] B. Grandchamp, N. Phung, Y. Nordmann, The mitochondrial localization of coproporphyrinogen III oxidase, Epub 1978/10/15, Biochem. J. 176 (1) (1978) 97-102, https://doi.org/10.1042/bj1760097. PubMed PMID: 31872; PMCID: PMC1186208.

[10] H.W. Rhee, P. Zou, N.D. Udeshi, J.D. Martell, V.K. Mootha, S.A. Carr, A.Y. Ting, Proteomic mapping of mitochondria in living cells via spatially restricted enzymatic tagging, Epub 2013/02/02, Science 339 (6125) (2013) 1328-1331, https://doi.org/10.1126/science.1230593. PubMed PMID: 23371551; PMCID: PMC3916822.

[11] Y.Y. Yien, R.F. Robledo, I.J. Schultz, N. Takahashi-Makise, B. Gwynn, D.E. Bauer, A. Dass, G. Yi, L. Li, G.J. Hildick-Smith, J.D. Cooney, E.L. Pierce, K. Mohler, T. A. Dailey, N. Miyata, P.D. Kingsley, C. Garone, S.M. Hattangadi, H. Huang, 
W. Chen, E.M. Keenan, D.I. Shah, T.M. Schlaeger, S. DiMauro, S.H. Orkin, A. B. Cantor, J. Palis, C.M. Koehler, H.F. Lodish, J. Kaplan, D.M. Ward, H.A. Dailey, J. D. Phillips, L.L. Peters, B.H. Paw, TMEM14C is required for erythroid mitochondrial heme metabolism, Epub 2014/08/27, J. Clin. Invest. 124 (10) (2014) 4294-4304, https://doi.org/10.1172/JCI76979. PubMed PMID: 25157825; PMCID: PMC4191016.

[12] B.M. Harbin, H.A. Dailey, Orientation of ferrochelatase in bovine liver mitochondria, Epub 1985/01/15, Biochemistry 24 (2) (1985) 366-370, https:// doi.org/10.1021/bi00323a019. PubMed PMID: 3884041.

[13] D.A. Hanna, O. Martinez-Guzman, A.R. Reddi, Heme gazing: illuminating eukaryotic heme trafficking, dynamics, and signaling with fluorescent heme sensors, Epub 2017/03/21, Biochemistry 56 (13) (2017) 1815-1823, https://doi. org/10.1021/acs.biochem.7b00007. PubMed PMID: 28316240; PMCID: PMC5629415.

[14] H.A. Dailey, P.N. Meissner, Erythroid heme biosynthesis and its disorders, Epub 2013/03/09, Cold Spring Harb Perspect Med 3 (4) (2013) a011676, https://doi org/10.1101/cshperspect.a011676. PubMed PMID: 23471474; PMCID: PMC3683999.

[15] M. Hoffman, M. Gora, J. Rytka, Identification of rate-limiting steps in yeast heme biosynthesis, Epub 2003/10/16, Biochem. Biophys. Res. Commun. 310 (4) (2003) 1247-1253, https://doi.org/10.1016/j.bbrc.2003.09.151. PubMed PMID: 14559249.

[16] J. Chung, J.G. Wittig, A. Ghamari, M. Maeda, T.A. Dailey, H. Bergonia, M. D. Kafina, E.E. Coughlin, C.E. Minogue, A.S. Hebert, L. Li, J. Kaplan, H.F. Lodish, D. E. Bauer, S.H. Orkin, A.B. Cantor, T. Maeda, J.D. Phillips, J.J. Coon, D.J. Pagliarini, H.A. Dailey, B.H. Paw, Erythropoietin signaling regulates heme biosynthesis, Epub 2017/05/30, Elife 6 (2017), https://doi.org/10.7554/eLife.24767. PubMed PMID: 28553927; PMCID: PMC5478267.

[17] A.E. Medlock, M.T. Shiferaw, J.R. Marcero, A.A. Vashisht, J.A. Wohlschlegel, J. D. Phillips, H.A. Dailey, Identification of the mitochondrial heme metabolism complex, Epub 2015/08/20, PloS One 10 (8) (2015), e0135896, https://doi.org/ 10.1371/journal.pone.0135896. PubMed PMID: 26287972; PMCID: PMC4545792.

[18] J.S. Burch, J.R. Marcero, J.A. Maschek, J.E. Cox, L.K. Jackson, A.E. Medlock, J. D. Phillips, H.A. Dailey Jr., Glutamine via alpha-ketoglutarate dehydrogenase provides succinyl-CoA for heme synthesis during erythropoiesis, Epub 2018/07/ 12, Blood 132 (10) (2018) 987-998, https://doi.org/10.1182/blood-2018-01 829036. PubMed PMID: 29991557; PMCID: PMC6128084.

[19] R.B. Piel 3rd, M.T. Shiferaw, A.A. Vashisht, J.R. Marcero, J.L. Praissman, J. D. Phillips, J.A. Wohlschlegel, A.E. Medlock, A novel role for progesterone receptor membrane component 1 (PGRMC1): a partner and regulator of ferrochelatase, Epub 2016/09/07, Biochemistry 55 (37) (2016) 5204-5217, https://doi.org/ 10.1021/acs.biochem.6b00756. PubMed PMID: 27599036; PMCID: PMC5278647.

[20] W. Chen, H.A. Dailey, B.H. Paw, Ferrochelatase forms an oligomeric complex with mitoferrin-1 and Abcb10 for erythroid heme biosynthesis, Epub 2010/04/30, Blood 116 (4) (2010) 628-630, https://doi.org/10.1182/blood-2009-12-259614. PubMed PMID: 20427704; PMCID: PMC3324294.

[21] N. Maio, K.S. Kim, G. Holmes-Hampton, A. Singh, T.A. Rouault, Dimeric ferrochelatase bridges ABCB7 and ABCB10 homodimers in an architecturally defined molecular complex required for heme biosynthesis, Epub 2019/02/16, Haematologica 104 (9) (2019) 1756-1767, https://doi.org/10.3324 haematol.2018.214320. PubMed PMID: 30765471; PMCID: PMC6717564.

[22] S. Taketani, K. Kakimoto, H. Ueta, R. Masaki, T. Furukawa, Involvement of ABC7 in the biosynthesis of heme in erythroid cells: interaction of ABC7 with ferrochelatase, Epub 2002/12/14, Blood 101 (8) (2003) 3274-3280, https://doi. org/10.1182/blood-2002-04-1212. PubMed PMID: 12480705

[23] J.R. Friedman, A. Mourier, J. Yamada, J.M. McCaffery, J. Nunnari, MICOS coordinates with respiratory complexes and lipids to establish mitochondrial inner membrane architecture, Epub 2015/04/29, Elife 4 (2015), https://doi.org/ 10.7554/eLife.07739. PubMed PMID: 25918844; PMCID: PMC4434539.

[24] V. Kozjak-Pavlovic, The MICOS complex of human mitochondria, Epub 2016/06/ 02, Cell Tissue Res. 367 (1) (2017) 83-93, https://doi.org/10.1007/s00441-0162433-7. PubMed PMID: 27245231.

[25] N. Pfanner, M. van der Laan, P. Amati, R.A. Capaldi, A.A. Caudy, A. Chacinska, M. Darshi, M. Deckers, S. Hoppins, T. Icho, S. Jakobs, J. Ji, V. Kozjak-Pavlovic, C. Meisinger, P.R. Odgren, S.K. Park, P. Rehling, A.S. Reichert, M.S. Sheikh, S. S. Taylor, N. Tsuchida, A.M. van der Bliek, I.J. van der Klei, J.S. Weissman, B. Westermann, J. Zha, W. Neupert, J. Nunnari, Uniform nomenclature for the mitochondrial contact site and cristae organizing system, Epub 2014/04/02, J. Cell Biol. 204 (7) (2014) 1083-1086, https://doi.org/10.1083/jcb.201401006. PubMed PMID: 24687277; PMCID: PMC3971754.

[26] M.J. Aaltonen, J.R. Friedman, C. Osman, B. Salin, J.P. di Rago, J. Nunnari, T. Langer, T. Tatsuta, MICOS and phospholipid transfer by Ups2-Mdm35 organize membrane lipid synthesis in mitochondria, Epub 2016/06/01, J. Cell Biol. 213 (5) (2016) 525-534, https://doi.org/10.1083/jcb.201602007. PubMed PMID: 27241913; PMCID: PMC4896057.

[27] K. Subramanian, A. Jochem, M. Le Vasseur, S. Lewis, B.R. Paulson, T.R. Reddy, J. D. Russell, J.J. Coon, D.J. Pagliarini, J. Nunnari, Coenzyme Q biosynthetic proteins assemble in a substrate-dependent manner into domains at ER-mitochondria contacts, Epub 2019/01/25, J. Cell Biol. 218 (4) (2019) 1353-1369, https://doi. org/10.1083/jcb.201808044. PubMed PMID: 30674579; PMCID: PMC6446851.

[28] E. Grzybowska, M. Gora, D. Plochocka, J. Rytka, Saccharomyces cerevisiae ferrochelatase forms a homodimer, Epub 2002/02/08, Arch. Biochem. Biophys. 398 (2) (2002) 170-178, https://doi.org/10.1006/abbi.2001.2730. PubMed PMID: 11831847.

[29] T. Karlberg, D. Lecerof, M. Gora, G. Silvegren, R. Labbe-Bois, M. Hansson, S. AlKaradaghi, Metal binding to Saccharomyces cerevisiae ferrochelatase, Epub 2002/
11/13, Biochemistry 41 (46) (2002) 13499-13506, https://doi.org/10.1021/ bi0260785. PubMed PMID: 12427010.

[30] B. Ho, A. Baryshnikova, G.W. Brown, Unification of protein abundance datasets yields a quantitative Saccharomyces cerevisiae proteome, e3. Epub 2018/01/24, Cell Syst 6 (2) (2018) 192-205, https://doi.org/10.1016/j.cels.2017.12.004. PubMed PMID: 29361465.

[31] H.A. Dailey, C.K. Wu, P. Horanyi, A.E. Medlock, W. Najahi-Missaoui, A.E. Burden, T.A. Dailey, J. Rose, Altered orientation of active site residues in variants of human ferrochelatase. Evidence for a hydrogen bond network involved in catalysis, Epub 2007/06/15, Biochemistry 46 (27) (2007) 7973-7979, https://doi.org/10.1021/ bi700151f. PubMed PMID: 17567154; PMCID: PMC2424199.

[32] B.R. Crouse, V.M. Sellers, M.G. Finnegan, H.A. Dailey, M.K. Johnson, Site-directed mutagenesis and spectroscopic characterization of human ferrochelatase: identification of residues coordinating the [2Fe-2S] cluster, Epub 1996/12/17, Biochemistry 35 (50) (1996) 16222-16229, https://doi.org/10.1021/bi9620114. PubMed PMID: 8973195.

[33] H.A. Dailey, M.G. Finnegan, M.K. Johnson, Human ferrochelatase is an iron-sulfur protein, Epub 1994/01/18, Biochemistry 33 (2) (1994) 403-407, https://doi.org/ 10.1021/bi00168a003. PubMed PMID: 8286370.

[34] H.A. Dailey, V.M. Sellers, T.A. Dailey, Mammalian ferrochelatase. Expression and characterization of normal and two human protoporphyric ferrochelatases, J. Biol. Chem. 269 (1) (1994) 390-395. Epub 1994/01/07. PubMed PMID: 8276824.

[35] V.M. Sellers, K.F. Wang, M.K. Johnson, H.A. Dailey, Evidence that the fourth ligand to the $[2 \mathrm{Fe}-2 \mathrm{~S}]$ cluster in animal ferrochelatase is a cysteine. Characterization of the enzyme from Drosophila melanogaster, Epub 1998/08/26, J. Biol. Chem. 273 (35) (1998) 22311-22316, https://doi.org/10.1074/jbc.273.35.22311. PubMed PMID: 9712849.

[36] H.J. Kim, M.Y. Jeong, T.J. Parnell, M. Babst, J.D. Phillips, D.R. Winge, The plasma membrane protein Nce102 implicated in eisosome formation rescues a heme defect in mitochondria, Epub 2016/06/19, J. Biol. Chem. 291 (33) (2016) 17417-17426, https://doi.org/10.1074/jbc.M116.727743. PubMed PMID: 27317660; PMCID: PMC5016138.

[37] E. Baruffini, T. Lodi, C. Dallabona, A. Puglisi, M. Zeviani, I. Ferrero, Genetic and chemical rescue of the Saccharomyces cerevisiae phenotype induced by mitochondrial DNA polymerase mutations associated with progressive external ophthalmoplegia in humans, Epub 2006/08/31, Hum. Mol. Genet. 15 (19) (2006) 2846-2855, https://doi.org/10.1093/hmg/ddl219. PubMed PMID: 16940310.

[38] N. Lecrenier, F. Foury, Overexpression of the RNR1 gene rescues Saccharomyces cerevisiae mutants in the mitochondrial DNA polymerase-encoding MIP1 gene, Epub 1995/11/01, Mol. Gen. Genet. 249 (1) (1995) 1-7, https://doi.org/10.1007/ BF00290229. PubMed PMID: 8552025.

[39] R. Zeng, E. Smith, A. Barrientos, Yeast mitoribosome large subunit assembly proceeds by hierarchical incorporation of protein clusters and modules on the inner membrane, e7. Epub 2018/03/08, Cell Metabol. 27 (3) (2018) 645-656, https:// doi.org/10.1016/j.cmet.2018.01.012. PubMed PMID: 29514071; PMCID: PMC5951612.

[40] A.E. Medlock, H.A. Dailey, Examination of the activity of carboxyl-terminal chimeric constructs of human and yeast ferrochelatases, Epub 2000/06/20, Biochemistry 39 (25) (2000) 7461-7467, https://doi.org/10.1021/bi000134p. PubMed PMID: 10858295.

[41] K. von der Malsburg, J.M. Muller, M. Bohnert, S. Oeljeklaus, P. Kwiatkowska, T. Becker, A. Loniewska-Lwowska, S. Wiese, S. Rao, D. Milenkovic, D.P. Hutu, R. M. Zerbes, A. Schulze-Specking, H.E. Meyer, J.C. Martinou, S. Rospert, P. Rehling, C. Meisinger, M. Veenhuis, B. Warscheid, I.J. van der Klei, N. Pfanner, A. Chacinska, M. van der Laan, Dual role of mitofilin in mitochondrial membrane organization and protein biogenesis, Epub 2011/09/29, Dev. Cell 21 (4) (2011) 694-707, https://doi.org/10.1016/j.devcel.2011.08.026. PubMed PMID: 21944719.

[42] H.A. Dailey, C.S. Jones, S.W. Karr, Interaction of free porphyrins and metalloporphyrins with mouse ferrochelatase. A model for the active site of ferrochelatase, Epub 1989/11/09, Biochim. Biophys. Acta 999 (1) (1989) 7-11, https://doi.org/10.1016/0167-4838(89)90021-6. PubMed PMID: 2804139.

[43] M. Hoggins, H.A. Dailey, C.N. Hunter, J.D. Reid, Direct measurement of metal ion chelation in the active site of human ferrochelatase, Epub 2007/06/15, Biochemistry 46 (27) (2007) 8121-8127, https://doi.org/10.1021/bi602418e. PubMed PMID: 17566985; PMCID: PMC2396339.

[44] D.A. Hanna, R.M. Harvey, O. Martinez-Guzman, X. Yuan, B. Chandrasekharan, G. Raju, F.W. Outten, I. Hamza, A.R. Reddi, Heme dynamics and trafficking factors revealed by genetically encoded fluorescent heme sensors, Epub 2016/06/02, Proc. Natl. Acad. Sci. U. S. A. 113 (27) (2016) 7539-7544, https://doi.org/ 10.1073/pnas.1523802113. PubMed PMID: 27247412; PMCID: PMC4941510.

[45] D.A. Hanna, R. Hu, H. Kim, O. Martinez-Guzman, M.P. Torres, A.R. Reddi, Heme bioavailability and signaling in response to stress in yeast cells, Epub 2018/06/21, J. Biol. Chem. 293 (32) (2018) 12378-12393, https://doi.org/10.1074/jbc. RA118.002125. PubMed PMID: 29921585; PMCID: PMC6093230.

[46] O. Martinez-Guzman, M.M. Willoughby, A. Saini, J.V. Dietz, I. Bohovych, A. E. Medlock, O. Khalimonchuk, A.R. Reddi, Mitochondrial-nuclear heme trafficking in budding yeast is regulated by GTPases that control mitochondrial dynamics and ER contact sites, Epub 2020/04/09, J. Cell Sci. 133 (10) (2020), https://doi.org/ 10.1242/jcs.237917. PubMed PMID: 32265272; PMCID: PMC7325432.

[47] M. Sachar, K.E. Anderson, X. Ma, Protoporphyrin IX: the good, the bad, and the ugly, Epub 2015/11/22, J. Pharmacol. Exp. Therapeut. 356 (2) (2016) 267-275, https://doi.org/10.1124/jpet.115.228130. PubMed PMID: 26588930; PMCID: PMC4727154.

[48] Y. Xiong, X. Tian, H.W. Ai, Molecular tools to generate reactive oxygen species in biological systems, Epub 2019/04/16, Bioconjugate Chem. 30 (5) (2019) 
1297-1303, https://doi.org/10.1021/acs.bioconjchem.9b00191. PubMed PMID: 30986044; PMCID: PMC6528174.

[49] M. Ethirajan, Y. Chen, P. Joshi, R.K. Pandey, The role of porphyrin chemistry in tumor imaging and photodynamic therapy, Epub 2010/08/10, Chem. Soc. Rev. 40 (1) (2011) 340-362, https://doi.org/10.1039/b915149b. PubMed PMID: 20694259.

[50] M.P. Viana, R.M. Levytskyy, R. Anand, A.S. Reichert, O. Khalimonchuk, Protease OMA1 modulates mitochondrial bioenergetics and ultrastructure through dynamic association with MICOS complex, Epub 2021/03/02, iScience 24 (2) (2021) 102119, https://doi.org/10.1016/j.isci.2021.102119. PubMed PMID: 33644718; PMCID: PMC7892988.

[51] D.I. Shah, N. Takahashi-Makise, J.D. Cooney, L. Li, I.J. Schultz, E.L. Pierce, A. Narla, A. Seguin, S.M. Hattangadi, A.E. Medlock, N.B. Langer, T.A. Dailey, S. N. Hurst, D. Faccenda, J.M. Wiwczar, S.K. Heggers, G. Vogin, W. Chen, C. Chen, D. R. Campagna, C. Brugnara, Y. Zhou, B.L. Ebert, N.N. Danial, M.D. Fleming, D. M. Ward, M. Campanella, H.A. Dailey, J. Kaplan, B.H. Paw, Mitochondrial Atpif regulates haem synthesis in developing erythroblasts, Epub 2012/11/09, Nature 491 (7425) (2012) 608-612, https://doi.org/10.1038/nature11536. PubMed PMID: 23135403; PMCID: PMC3504625.

[52] E. Bradshaw, M. Yoshida, F. Ling, Regulation of small mitochondrial DNA replicative advantage by ribonucleotide reductase in Saccharomyces cerevisiae, Epub 2017/07/19, G3 (Bethesda) 7 (9) (2017) 3083-3090, https://doi.org/ 10.1534/g3.117.043851. PubMed PMID: 28717049; PMCID: PMC5592933.

[53] I.C. Soto, A. Barrientos, Mitochondrial cytochrome c oxidase biogenesis is regulated by the redox state of a heme-binding translational activator, Epub 2015/ 09/29, Antioxid Redox Signal 24 (6) (2016) 281-298, https://doi.org/10.1089/ ars.2015.6429. PubMed PMID: 26415097; PMCID: PMC4761835.

[54] I.C. Soto, F. Fontanesi, R.S. Myers, P. Hamel, A. Barrientos, A heme-sensing mechanism in the translational regulation of mitochondrial cytochrome c oxidase biogenesis, Epub 2012/12/12, Cell Metabol. 16 (6) (2012) 801-813, https://doi. org/10.1016/j.cmet.2012.10.018. PubMed PMID: 23217259; PMCID: PMC3523284.

[55] N. Cassanova, K.M. O’Brien, B.T. Stahl, T. McClure, R.O. Poyton, Yeast flavohemoglobin, a nitric oxide oxidoreductase, is located in both the cytosol and the mitochondrial matrix: effects of respiration, anoxia, and the mitochondrial genome on its intracellular level and distribution, Epub 2004/12/22, J. Biol. Chem. 280 (9) (2005) 7645-7653, https://doi.org/10.1074/jbc.M411478200. PubMed PMID: 15611069.

[56] L. Liu, M. Zeng, A. Hausladen, J. Heitman, J.S. Stamler, Protection from nitrosative stress by yeast flavohemoglobin, Epub 2000/04/12, Proc. Natl. Acad. Sci. U. S. A 97 (9) (2000) 4672-4676, https://doi.org/10.1073/pnas.090083597. PubMed PMID: 10758168; PMCID: PMC18291.

[57] L.M. de Godoy, J.V. Olsen, J. Cox, M.L. Nielsen, N.C. Hubner, F. Frohlich, T. C. Walther, M. Mann, Comprehensive mass-spectrometry-based proteome quantification of haploid versus diploid yeast, Epub 2008/09/30, Nature 455 (7217) (2008) 1251-1254, https://doi.org/10.1038/nature07341. PubMed PMID 18820680 .

[58] M. Zagorec, R. Labbe-Bois, Negative control of yeast coproporphyrinogen oxidas synthesis by heme and oxygen, J. Biol. Chem. 261 (6) (1986) 2506-2509. Epub 1986/02/25. PubMed PMID: 3512538.

[59] M.A. Huynen, M. Muhlmeister, K. Gotthardt, S. Guerrero-Castillo, U. Brandt, Evolution and structural organization of the mitochondrial contact site (MICOS) complex and the mitochondrial intermembrane space bridging (MIB) complex, Epub 2015/10/21, Biochim. Biophys. Acta 1863 (1) (2016) 91-101, https://doi. org /10.1016/j.bbamcr.2015.10.009. PubMed PMID: 26477565.

[60] S.A. Munoz-Gomez, C.H. Slamovits, J.B. Dacks, K.A. Baier, K.D. Spencer, J. G. Wideman, Ancient homology of the mitochondrial contact site and cristae organizing system points to an endosymbiotic origin of mitochondrial cristae, Epub 2015/05/26, Curr. Biol. 25 (11) (2015) 1489-1495, https://doi.org/10.1016/j cub.2015.04.006. PubMed PMID: 26004762.

[61] A.E. Medlock, W. Najahi-Missaoui, T.A. Ross, T.A. Dailey, J. Burch, J.R. O'Brien, W.N. Lanzilotta, H.A. Dailey, Identification and characterization of solvent-filled channels in human ferrochelatase, Epub 2012/06/21, Biochemistry 51 (27) (2012) 5422-5433, https://doi.org/10.1021/bi300598g. PubMed PMID: 22712763; PMCID: PMC3448031.

[62] A.R. Prasad, H.A. Dailey, Effect of cellular location on the function of ferrochelatase, Epub 1995/08/04, J. Biol. Chem. 270 (31) (1995) 18198-18200, https://doi.org/10.1074/jbc.270.31.18198. PubMed PMID: 7629135.

[63] H. Lin, L. Li, X. Jia, D.M. Ward, J. Kaplan, Genetic and biochemical analysis of high iron toxicity in yeast: iron toxicity is due to the accumulation of cytosolic iron and occurs under both aerobic and anaerobic conditions, Epub 2010/12/01, J. Biol. Chem. 286 (5) (2011) 3851-3862, https://doi.org/10.1074/jbc.M110.190959. PubMed PMID: 21115478; PMCID: PMC3030386.

[64] F. Sherman, Getting started with yeast, Epub 2002/06/21, Methods Enzymol. 350 2002) 3-41, https://doi.org/10.1016/s0076-6879(02)50954-x. PubMed PMID: 12073320.

[65] R.J. Crisp, A. Pollington, C. Galea, S. Jaron, Y. Yamaguchi-Iwai, J. Kaplan, Inhibition of heme biosynthesis prevents transcription of iron uptake genes in yeast, Epub 2003/08/21, J. Biol. Chem. 278 (46) (2003) 45499-45506, https:// doi.org/10.1074/jbc.M307229200. PubMed PMID: 12928433.

[66] F. Marchal, R. Peslin, C. Duvivier, C. Gallina, J.P. Crance, Measurement of ventilatory mechanical impedance in infants using a head pressure generator, Epub 1989/01/01, Pediatr. Pulmonol. 7 (4) (1989) 209-216, https://doi.org/10.1002/ ppul.1950070405. PubMed PMID: 2694087.

[67] I. Bohovych, G. Donaldson, S. Christianson, N. Zahayko, O. Khalimonchuk, Stresstriggered activation of the metalloprotease Oma1 involves its C-terminal region and is important for mitochondrial stress protection in yeast, Epub 2014/03/22, J. Biol. Chem. 289 (19) (2014) 13259-13272, https://doi.org/10.1074/jbc. M113.542910. PubMed PMID: 24648523; PMCID: PMC4036336.

[68] S. Swenson, A. Cannon, N.J. Harris, N.G. Taylor, J.L. Fox, O. Khalimonchuk, Analysis of oligomerization properties of heme a synthase provides insights into its function in eukaryotes, Epub 2016/03/05, J. Biol. Chem. 291 (19) (2016) 10411-10425, https://doi.org/10.1074/jbc.M115.707539. PubMed PMID: 26940873; PMCID: PMC4858986.

[69] E.A. Berry, B.L. Trumpower, Simultaneous determination of hemes a, b, and c from pyridine hemochrome spectra, Epub 1987/02/15, Anal. Biochem. 161 (1) (1987) 1-15, https://doi.org/10.1016/0003-2697(87)90643-9. PubMed PMID: 3578775.

[70] J.R. Marcero, R.B. Piel Iii, J.S. Burch, H.A. Dailey, Rapid and sensitive quantitation of heme in hemoglobinized cells, Epub 2016/08/17, Biotechniques 61 (2) (2016) 83-91, https://doi.org/10.2144/000114444. PubMed PMID: 27528073.

[71] K.G. Paul, H. Theorell, A. Akeson, The molar light absorption of pyridine ferroprotoporphyrin (pyridine haemochromogen), Acta Chem. Scand. 7 (9) (1953) 1284-1287, https://doi.org/10.3891/acta.chem.scand.07-1284. PubMed PMID: WOS:A1953UW38600010.

[72] A.E. Burden, C. Wu, T.A. Dailey, J.L. Busch, I.K. Dhawan, J.P. Rose, B. Wang, H. A. Dailey, Human ferrochelatase: crystallization, characterization of the [2Fe-2S cluster and determination that the enzyme is a homodimer, Epub 1999/11/24, Biochim. Biophys. Acta 1435 (1-2) (1999) 191-197, https://doi.org/10.1016/ s0167-4838(99)00196-x. PubMed PMID: 10561552.

[73] J.M. Frustaci, M.R. O'Brian, The Escherichia coli visA gene encodes ferrochelatase, the final enzyme of the heme biosynthetic pathway, Epub 1993/04/01, J. Bacteriol. 175 (7) (1993) 2154-2156, https://doi.org/10.1128/jb.175.7.2154 2156.1993. PubMed PMID: 8458858; PMCID: PMC204334

[74] K. Miyamoto, K. Nakahigashi, K. Nishimura, H. Inokuchi, Isolation and characterization of visible light-sensitive mutants of Escherichia coli K12, Epub 1991/06/05, J. Mol. Biol. 219 (3) (1991) 393-398, https://doi.org/10.1016/00222836(91)90180-e. PubMed PMID: 2051480.

[75] A.T. Brunger, Version 1.2 of the crystallography and NMR system, Nat. Protoc. 2 (11) (2007) 2728-2733. Epub 2007/11/17. doi: nprot.2007.406 [pii] 10.1038/ nprot.2007.406. PubMed PMID: 18007608

[76] P. Emsley, B. Lohkamp, W.G. Scott, K. Cowtan, Features and development of coot, Epub 2010/04/13, Acta Crystallogr D Biol Crystallogr 66 (Pt 4) (2010) 486-501, https://doi.org/10.1107/S0907444910007493. PubMed PMID: 20383002; PMCID: PMC2852313.

[77] The PyMOL Molecular Graphics System. Version 1.3 ed: Schrödinger, LLC

[78] K. Diekert, A.I. de Kroon, G. Kispal, R. Lill, Isolation and subfractionation of mitochondria from the yeast Saccharomyces cerevisiae, Epub 2001/05/31, Methods Cell Biol. 65 (2001) 37-51, https://doi.org/10.1016/s0091-679x(01) 65003-9. PubMed PMID: 11381604

[79] A. Atkinson, O. Khalimonchuk, P. Smith, H. Sabic, D. Eide, D.R. Winge, Mzm1 influences a labile pool of mitochondrial zinc important for respiratory function, Epub 2010/04/21, J. Biol. Chem. 285 (25) (2010) 19450-19459, https://doi.org/ 10.1074/jbc.M110.109793. PubMed PMID: 20404342; PMCID: PMC2885224.

[80] O. Khalimonchuk, M. Bestwick, B. Meunier, T.C. Watts, D.R. Winge, Formation of the redox cofactor centers during Cox1 maturation in yeast cytochrome oxidase, Epub 2009/12/10, Mol. Cell Biol. 30 (4) (2010) 1004-1017, https://doi.org/ 10.1128/MCB.00640-09. PubMed PMID: 19995914; PMCID: PMC2815561.

[81] E.M. Germany, N. Zahayko, M.L. Huebsch, J.L. Fox, V. Prahlad, O. Khalimonchuk, The AAA ATPase Afg1 preserves mitochondrial fidelity and cellular health by maintaining mitochondrial matrix proteostasis, Epub 2018/10/12, J. Cell Sci. 131 (22) (2018), https://doi.org/10.1242/jcs.219956. PubMed PMID: 30301782; PMCID: PMC6262775.

[82] E.A. Sweeny, A.B. Singh, R. Chakravarti, O. Martinez-Guzman, A. Saini, M. M. Haque, G. Garee, P.D. Dans, L. Hannibal, A.R. Reddi, D.J. Stuehr, Glyceraldehyde-3-phosphate dehydrogenase is a chaperone that allocates labile heme in cells, Epub 2018/07/18, J. Biol. Chem. 293 (37) (2018) 14557-14568, https://doi.org/10.1074/jbc.RA118.004169. PubMed PMID: 30012884; PMCID: PMC6139559.

[83] P.S. Ebert, R.A. Hess, B.C. Frykholm, D.P. Tschudy, Succinylacetone, a poten inhibitor of heme biosynthesis: effect on cell growth, heme content and deltaaminolevulinic acid dehydratase activity of malignant murine erythroleukemia cells, Epub 1979/06/27, Biochem. Biophys. Res. Commun. 88 (4) (1979) 1382-1390, https://doi.org/10.1016/0006-291x(79)91133-1. PubMed PMID: 289386. 